\title{
Kinetic characterization and thermostability of $C$. elegans cytoplasmic and mitochondrial malate dehydrogenases
}

\author{
Matthew J. Thomas ${ }^{1}$, Emma R. Cassidy², Devin S. Robinson², Katherine M. \\ Walstrom ${ }^{2}$
}

${ }^{1}$ Department of Natural Sciences, State College of Florida, Bradenton, FL 34207, USA

${ }^{2}$ Division of Natural Sciences, New College of Florida, Sarasota, FL 34243, USA

*For correspondence: Katherine M. Walstrom, walstrom@ncf.edu, ORCID ID: 0000-0002-8896-3850

Running title: Kinetics and stability of malate dehydrogenases

Key words: dehydrogenase, enzyme kinetics, protein stability, metabolism, homology modeling, $C$. elegans 


\begin{abstract}
Malate dehydrogenase $(\mathrm{MDH})$ catalyzes the conversion of $\mathrm{NAD}^{+}$and malate to $\mathrm{NADH}$ and oxaloacetate in the last step of the citric acid cycle. Eukaryotes have at least two $\mathrm{MDH}$ isozymes, one that is imported into the mitochondria and one that remains in the cytoplasm. We overexpressed and purified Caenorhabditis elegans cytoplasmic MDH-1 (F46E10.10) and mitochondrial MDH-2 (F2OH11.3) in $E$. coli. Our goal was to compare the kinetic and structural properties of these enzymes because $C$. elegans can survive adverse environmental conditions, such as lack of food and elevated temperatures. In steady-state enzyme kinetics assays, we determined that the $K_{\mathrm{M}}$ values for oxaloacetate were 54 and $52 \mu \mathrm{M}$, and the $K_{\mathrm{M}}$ values for $\mathrm{NADH}$ were 61 and $107 \mu \mathrm{M}$, for $\mathrm{MDH}-1$ and $\mathrm{MDH}-2$, respectively. We partially purified endogenous $\mathrm{MDH}$ from a mixed population of worms and separated $\mathrm{MDH}-1$ from $\mathrm{MDH}-2$ using anion exchange chromatography. Both endogenous enzymes had a $K_{\mathrm{M}}$ for oxaloacetate similar to that of the corresponding recombinant enzyme. The reaction velocities of the recombinant enzymes had slightly different temperature-dependencies: MDH-1 and $\mathrm{MDH}-2$ had maximum activity at $40^{\circ} \mathrm{C}$ and $35^{\circ} \mathrm{C}$, respectively. In a thermotolerance assay, $\mathrm{MDH}-1$ was much more thermostable than $\mathrm{MDH}-2$. Molecular homology modeling predicted that $\mathrm{MDH}-1$ had more salt-bridges between the subunits than mammalian MDH1 enzymes, and these ionic interactions may contribute to its thermostability. In contrast, the MDH-2 homology model predicted fewer ionic interaction between the subunits compared to mammalian $\mathrm{MDH} 2$ enzymes. These results suggest that the increased structural stability of $\mathrm{MDH}-1$ may facilitate its ability to remain active in adverse environmental conditions. In contrast, $\mathrm{MDH}-2$ may use other strategies, such as protein binding partners, to function under similar conditions.
\end{abstract}




\section{Introduction}

Malate dehydrogenase $\left(\mathrm{MDH}^{1}\right)$ is a central enzyme connecting the citric acid cycle, gluconeogenesis, and the glyoxylate shunt. Eukaryotes contain at least two different isozymes. Mitochondrial MDH2 participates in the citric acid cycle, and cytoplasmic MDH1 has numerous functions because it is an enzyme connecting glycolysis and gluconeogenesis to a variety of reactions occurring in the mitochondria. MDH from many different organisms ranging from archaea to plants to mammals have been studied previously (reviewed in (1-3)). Studies of $\mathrm{MDH}$ enzymes from invertebrates have been done, and most of these involved parasitic tapeworms and flukes (4-9). In this study, we characterized Caenorhabditis elegans MDH enzymes to determine how the enzymes may be optimized to function in an organism that can withstand intermittent harsh environmental conditions.

Overcrowding and lack of available food can induce $C$. elegans to enter a state of developmental arrest called dauer diapause (reviewed in (10)). Elevated temperatures can also induce dauer formation $(11,12)$. C. elegans can be arrested as dauers for up to 60 days and still recover and return to a normal postdauer lifespan (13). Dauer larvae do not feed, but they remain metabolically active. Specifically, dauers contain increased levels of fat and the protective disaccharide trehalose (1-O-alpha-D-glucopyranosyl-alpha-D-glucopyranoside), and the glyoxylate shunt and fermentation pathways are up-regulated (14-17).

The glyoxylate shunt is in the mitochondria in C. elegans. Isocitrate and acetyl CoA molecules enter this pathway to produce succinate and malate via the bifunctional isocitrate lyase/malate synthase enzyme ICL-1 (14, 18-21). Malate can participate in multiple metabolic pathways in the mitochondria or be exported out of the mitochondria. In the latter case, cytoplasmic MDH1 converts malate to oxaloacetate, which enters gluconeogenesis when it is converted to phosphoenolpyruvate (PEP) by PEP carboxykinase. Dauer larvae rely on stored triacylglycerols for energy. Since they are not feeding and consuming sugars, the glyoxylate pathway allows for the degradation of stored lipids to acetyl-CoA and the subsequent production of net oxaloacetate to form glycolytic intermediates and trehalose (14).

\footnotetext{
${ }^{1}$ Abbreviations: $\mathrm{MDH}$, malate dehydrogenase in general or bacterial $\mathrm{MDH} ; \mathrm{MDH}-1, \mathrm{C}$. elegans cytoplasmic $\mathrm{MDH}-1$; MDH-2, C. elegans mitochondrial MDH-2; MDH1, mammalian cytoplasmic $\mathrm{MDH} 1 ; \mathrm{MDH} 2$, mammalian mitochondrial MDH2; $m d h-1$, the gene encoding $\mathrm{MDH}-1 ; m d h-2$, the gene encoding $\mathrm{MDH}-2$
} 
The structure, function, and stability of MDH enzymes have been well studied in other other organisms. Numerous crystal structures are available, including structures of thermostable enzymes (22-26). Eukaryotic and bacterial MDH enzymes are usually homodimers, while archaeal MDH enzymes are usually homotetramers $(2,27-31)$. In this project, we sought to characterize the enzyme kinetic properties of recombinant and endogenous C. elegans MDH-1 and $\mathrm{MDH}-2$. We found that the cytoplasmic isozyme, MDH-1, was very thermostable. We then used protein homology modeling to determine possible structural features to explain this stability.

\section{Experimental Procedures}

\section{Sequence analysis}

The protein sequences from WormBase (wormbase.org) for C. elegans $\mathrm{MDH}-1$ (F46E10.10) and MDH-2 (F2OH11.3) were aligned with Sus scrofa MDH1 (NP_999039.1) and MDH2 (NP_001231082.1), human MDH1 (NP_005908.1) and MDH2 (P40926.3), Thermus thermophilus (NCBI:txid274, also called Thermus flavus) MDH (P10584.1), and E. coli MDH (QIF74064.1) sequences from the National Center for Biotechnology Information (NCBI) using Clustal Omega (32). The MDH-2 sequence was analyzed using MitoProt II v1.101 (33) and MitoFates (34) to determine the cleavage site for the mitochondrial import sequence.

\section{Plasmid Construction}

The $m d h-1$ gene was amplified from a mixed population of wild type (Bristol N2) C. elegans (NCBI:txid6239) cDNA using primers F46E10_10start, 5'GGGAATTCCATATGTCCGCCCCACTTCGC - 3' and F46E10_10end (5'-GGGCAACTAGTGCATCTCCCGTGATGCATGCGATGTTGGCATCATCGCAA GC C- 3'). This PCR product was cut with Ndel and Spel and ligated into the plasmid pTXB1 (New England Biolabs, NEB) that was also cut with Ndel and Spel. The sequence of the resulting plasmid was verified by dideoxynucleotide sequencing. The cleaved protein sequence had one extra Ala added to the $\mathrm{C}$-terminus to improve cleavage from the intein tag used for enzyme purification (see below). 
The $m d h-2$ sequence (with the mitochondrial import sequence removed) was amplified from the cDNA plasmid yk167 (a gift from the Yuji Kohara lab) using the primers MDH_N_Long (5'-GGTTTAGCTAGCAGCCAAGCTCCAAAGGTC) and MDH_C_Long (5'-ATGAACTCGAGGTTTCCCTTAACGAAAGCGACTCCCT). The PCR product was cut with Nhel and Xhol and ligated into plasmid pTXB1 that was previously cut with Nhel and Xhol. Then the C-terminal amino acid of $\mathrm{MDH}-2$ was mutated from Ser to Ala to improve the intein cleavage efficiency (see below). This was done using the QuickChange method (Stratagene) and the DNA oligomer 5'- GGAAACCTCGAGGGCTCTG*'CG*TGCATCACGGGAG, where the asterisks mark the altered nucleotides that changed the TCC codon to a GCG codon. The mutated plasmid sequence was verified. Recombinant $\mathrm{MDH}-2$ after intein cleavage had an extra MA sequence on the $\mathrm{N}$-terminus and an extra LEGSA sequence on the $\mathrm{C}$-terminus.

\section{Recombinant Enzyme Expression and purification.}

Both recombinant enzymes were expressed in freshly transformed Rosetta $E$. coli cells (EMD Biosciences) grown in terrific broth (1.2\% tryptone, $2.4 \%$ yeast extract, $0.4 \%$ glycerol, $0.017 \mathrm{M} \mathrm{KH}_{2} \mathrm{PO}_{4}, 0.072 \mathrm{M} \mathrm{K}_{2} \mathrm{HPO}_{4}$ ) and $0.1 \mathrm{mg} / \mathrm{mL}$ ampicillin to a density of OD600 $=0.4-0.5$. MDH-1 was expressed using $0.05 \mathrm{mM}$ IPTG in cells grown for $20 \mathrm{hr}$ at $25^{\circ} \mathrm{C}$. MDH-2 was expressed using $0.1 \mathrm{mM}$ IPTG in cells grown for $16 \mathrm{hr}$ at $25^{\circ} \mathrm{C}$. The cells were pelleted and stored at $-20^{\circ} \mathrm{C}$ until the enzymes were purified. Both enzymes were expressed as a fusion protein with a self-cleaving intein and a chitin binding domain (CBD) on the $\mathrm{C}$-terminus. The fusion proteins were purified on chitin resin using the IMPACT ${ }^{\mathrm{TM}}$ expression system (New England Biolabs) according to the manufacturer's instructions. The cleavage buffer $(20 \mathrm{mM}$ Tris- $\mathrm{HCl}, \mathrm{pH} 8.5,0.5 \mathrm{M} \mathrm{NaCl}, 50 \mathrm{mM}$ DTT) for the $\mathrm{MDH}-1$ purification included $0.2 \%$ Tween 20 to facilitate elution of the cleaved enzyme, and the cleavage was performed over 96 hours at $25^{\circ} \mathrm{C}$. Then the eluted protein was run over a fresh chitin column to remove remaining $\mathrm{MDH}-1-\mathrm{CBD}$ fusion protein and additional cleaved CBD (see supporting Figure S1). MDH-2 cleavage was performed in cleavage buffer over 24 hours at $4-6{ }^{\circ} \mathrm{C}$. Protein samples were analyzed using homemade 10-11\% Laemmli SDS-PAGE gels stained with Coomassie blue $(35,36)$. The gels were photographed with a digital camera, and the contrast in the images was improved using "Levels" in Adobe Photoshop 22.4.2. Enzyme fractions with comparable purity were combined and dialyzed into dialysis buffer ( $30 \mathrm{mM}$ potassium phosphate, $\mathrm{pH} 7.5$, $0.1 \mathrm{M} \mathrm{KCl}$, and $30 \%$ glycerol) before storage at $-20^{\circ} \mathrm{C}$. Protein concentrations were determined using a Coomassie Plus (Bradford) Assay kit (Pierce ${ }^{\mathrm{TM}}$ ). Predicted protein molecular weights, amino acid composition, and theoretical pl values were calculated using the ProtParam tool at Expasy.org. Our gel filtration 
results indicated that both recombinant $\mathrm{MDH}-1$ and $\mathrm{MDH}-2$ were active as dimers (data not shown).

\section{Endogenous enzyme purification}

C. elegans wild type (Bristol N2) hermaphrodites were obtained from the Caenorhabditis Genetics Center and grown on OP50 E. coli on egg plates (37) at $20^{\circ} \mathrm{C}$. Then they were collected, rinsed extensively in sterile M9 buffer $(3 \mathrm{~g}$ $\mathrm{KH}_{2} \mathrm{PO}_{4}, 6 \mathrm{~g} \mathrm{Na}_{2} \mathrm{HPO}_{4}, 5 \mathrm{~g} \mathrm{NaCl}, 1 \mathrm{mM} \mathrm{MgSO}_{4}$ per liter) to remove the bacterial food, pelleted, and stored at $-80^{\circ} \mathrm{C}$. Frozen worms were lysed in $20 \mathrm{mM}$ Tris- $\mathrm{HCl}$, pH 8.0, 150 mM NaCl, 0.1\% Tween 20, 1 mM DTT, and 1X Roche Complete ULTRA, EDTA-free protease inhibitors. Lysis was performed on ice using $4 \times 10$ $\mathrm{s}, 14 \mathrm{~W}$ pulses from a probe sonicator (Fisher Scientific) with $50 \mathrm{~s}$ pauses between each pulse. The mixture was spun at $22 \mathrm{~K} \mathrm{rcf}$ at $4{ }^{\circ} \mathrm{C}$ for $15 \mathrm{~min}$. To exchange the buffer and remove high molecular weight proteins, the supernatant (clarified lysate) was loaded onto a $7 \mathrm{~cm}$ high, $1.5 \mathrm{~cm}$ dia. P-100 or P-200 BioGel (BioRad) gel filtration column equilibrated in 50 mM CAPS, pH 9.5 and $10 \mathrm{mM}$ $\mathrm{KCl}$. Fractions containing $\mathrm{MDH}$ activity (excluding the first fraction) were loaded onto a $0.3 \mathrm{~mL}$ DEAE Sepharose FastFlow (GE Healthcare) column equilibrated with the same buffer. The flow-through (containing MDH-2) was collected, and the column was rinsed with five $0.5 \mathrm{~mL}$ additions of the same buffer. Then $50 \mathrm{mM}$ CAPS, pH 9.5 and $50 \mathrm{mM} \mathrm{KCl}$ was added to the column to elute $\mathrm{MDH}-1$, and five $0.5 \mathrm{ml}$ fractions were collected. These enzyme samples were used for enzyme kinetics measurements immediately after elution and then dialyzed into the dialysis buffer listed above. Protein concentrations were measured as described above. The rest of the MDH-2 flow-through fractions were mixed with two volumes of $50 \mathrm{mM}$ potassium phosphate, $\mathrm{pH} 7.5$, and loaded onto a $0.4 \mathrm{~mL}$ Blue Sepharose column (Sigma-Aldrich) that was equilibrated with the same buffer. This column was washed with $50 \mathrm{mM}$ potassium phosphate, $\mathrm{pH} 7.5$, and $100 \mathrm{mM}$ $\mathrm{KCl}$, and $\mathrm{MDH}-2$ was eluted with $50 \mathrm{mM}$ potassium phosphate, $\mathrm{pH} 7.5$, and 600 $\mathrm{mM} \mathrm{KCl}$. A small amount of the eluted sample was diluted 100-fold into enzyme kinetics assays, and the rest was concentrated with a Microcon 50 (Millipore). The protein samples were analyzed using SDS-PAGE gels and photographed as described above except that a silver stain was used to visualize the proteins (38).

\section{Enzyme Kinetics}

$\mathrm{MDH}-1$ and $\mathrm{MDH}-2$ are classified as EC 1.1.1.37. The reagents were purchased from Sigma-Aldrich or ThermoFisher, and oxaloacetate and $\mathrm{NAD}^{+}$solutions were prepared fresh each day. Enzyme kinetics assays were performed in assay buffer (0.1 M phosphate buffer, $\mathrm{pH} 7.5$, and $0.1 \mathrm{M} \mathrm{KCl}$ at $24^{\circ} \mathrm{C}$ ). This same buffer was 
used when the temperature was varied. For the kinetics experiments, MDH-1 was stored on ice and $\mathrm{MDH}-2$ was stored in a benchtop cooler that had been cooled to $-20{ }^{\circ} \mathrm{C}$. We did not notice a significant decrease in enzyme activity during the experiments. The enzymes were diluted 1:100 into assay buffer at 24 ${ }^{\circ} \mathrm{C}$. To measure the disappearance of $\mathrm{NADH}$, the solutions were monitored continuously at $340 \mathrm{~nm}$ for 30-60 s using an Olis-upgraded Cary 14 or a Cary 300 UV-Vis spectrophotometer, and the slopes of the lines were measured. Experiments with oxaloacetate varying from $0-250 \mu \mathrm{M}$ included $100 \mu \mathrm{M}$ NADH. Experiments with NADH varying from 0 - $350 \mu \mathrm{M}$ included $150 \mu \mathrm{M}$ oxaloacetate. Some of the measurements at lower [NADH] for MDH-2 (Figure 4C) were performed in $0.1 \mathrm{M}$ phosphate, $\mathrm{pH} 7.0$, and $0.1 \mathrm{M} \mathrm{KCl}$. All enzyme kinetics parameters were determined from non-linear least-squares fits of the data to the Michaelis-Menten equation using RStudio (version 1.4.1106).

The assays at different temperatures were performed in assay buffer containing $150 \mu \mathrm{M}$ oxaloacetate and $100 \mu \mathrm{M}$ NADH that had been incubated at the assay temperature for at least $5 \mathrm{~min}$. The cuvette was also pre-incubated at the assay temperature for at least $5 \mathrm{~min}$. For the heat tolerance experiments, the $\mathrm{MDH}-1$ and $\mathrm{MDH}-2$ enzymes were incubated at $55^{\circ} \mathrm{C}$ in $50 \mathrm{mM}$ Tris buffer, $\mathrm{pH} 7.5$, and $0.5 \mathrm{mM}$ NADH for the times indicated before they were diluted 100 -fold into assay buffer containing $150 \mu \mathrm{M}$ oxaloacetate and $100 \mu \mathrm{M} \mathrm{NADH}$ at $24{ }^{\circ} \mathrm{C}$.

To calculate specific activities for the endogenous enzymes, the units of enzyme activity were calculated based on the velocities measured in assay buffer containing $150 \mu \mathrm{M}$ oxaloacetate and $100 \mu \mathrm{M}$ NADH at $24{ }^{\circ} \mathrm{C}$. For the recombinant enzymes, the specific activities and $\mathrm{k}_{\text {cat }}$ values were calculated based on the $\mathrm{V}_{\max }$ values when $\mathrm{NADH}$ was varied.

\section{Protein Molecular Modeling and Structure Analysis}

The MDH-1 and MDH-2 sequences were submitted to SWISS-MODEL (39), and the predicted structures were built using ProMod3 (version 3.2.0, (40)) with the crystal structures 1BMD.1.A (25) and 2DFD.1.A (unpublished structure from the Structural Genomics Consortium) as the templates, respectively. The models had GMQE and QMEAN scores (41) of 0.79 and -0.62 , respectively, for $\mathrm{MDH}-1$ and 0.78 and -0.04 , respectively, for $\mathrm{MDH}-2$. The structure of the $\mathrm{MDH}-1$ model was refined by minimizing the free energy using the YASARA energy minimization server (42). The z-scores for the modeled structures were calculated using the ProSA-web tools $(43,44)$, the bond and rotamer angles were checked using MolProbity $(45,46)$, and the models passed the Verify 3D assessment (47-49). The results from these enzyme structure tests are shown in the supporting 
information Figures S3-S5. UCSF Chimera (version 1.15.0) (50) was used to search for intersubunit hydrogen-bonds (with constraints relaxed by $0.4 \AA$ and 20 degrees) involving charged amino acids. UCSF Chimera was also used to search for intersubunit hydrogen bonds in 5MDH (51) and 1BMD (25), and these results corresponded to the published lists of intersubunit hydrogen bonds in both structures $(22,25)$. The structures of S. scrofa MDH2 (1MLD) and an unpublished human MDH2 structure (4WLU) were obtained from the PDB and analyzed for intersubunit hydrogen bonds, and the $S$. scrofa $\mathrm{MDH} 2$ interactions mostly agreed with published results (23), as explained in Table 5. The PyMOL Molecular Graphics System (Version 2.4.2, Schrödinger, LLC) was used to measure distances, visualize the subunit interactions, and produce the structure figures. Amino acid composition was analyzed using the ProtParam tool at ExPASy.org. The protein structure volumes were measured using UCSF Chimera with the default settings. See the supporting information for additional protein modeling experimental details.

\section{Results}

\section{C. elegans $\mathrm{MDH}-1$ and $\mathrm{MDH}-2$ sequence analysis}

The cytoplasmic MDH in C. elegans (F46E10.10) was identified by Holt and Riddle (52), and we identified the mitochondrial enzyme (F20H11.3) by sequence homology. These enzymes were named MDH-1 and MDH-2, respectively, to conform with the naming convention used for MDH enzymes in other eukaryotes. An alignment of the $C$. elegans enzymes with Sus scrofa MDH1 and MDH2, human $\mathrm{MDH} 1$ and $\mathrm{MDH} 2$, Thermus thermophilus $\mathrm{MDH}$, and E. coli $\mathrm{MDH}$ is shown in Figure 1 with a phylogenetic tree and sequence identity tables. As expected, the mitochondrial enzymes were most similar to each other, as were the cytoplasmic enzymes. The T. thermophilus sequence was more similar to the cytoplasmic enzymes, and the E. coli sequence was more similar to the mitochondrial enzymes, and both of these results have been discussed previously $(1,2)$.

The amino acid numbering in Figure 1 corresponds to previous publications. Specifically, the papers describing the structures of $S$. scrofa MDH1 and $T$. thermophilus MDH both used the amino acid numbering of Birktoft, et al. (1989), which started at number 1 for the second amino acid of T. thermophilus MDH (because the $S$. scrofa MDH1 lacks the methionine) $(22,25)$. The $C$. elegans $\mathrm{MDH}-1$ amino acid numbers in this paper follow the S. scrofa MDH1 numbering in Figure 1, even though MDH-1 goes out of register by one amino acid between amino acids $142-275$ because of an amino acid deletion and addition in two 
exterior loops (data not shown). The paper describing the S. scrofa MDH2 structure started numbering at the first amino acid of the cleaved protein (23), and this convention is used here for all the mitochondrial $\mathrm{MDH}$ proteins. Since $\mathrm{MDH}-2$ has 4 extra amino acids on its $\mathrm{N}$-terminus compared to the other MDH2 enzymes, the amino acid numbering for S. scrofa was used for $\mathrm{MDH}-2$ and the mammalian MDH2 enzymes.

The substrate-binding and active site residues that have been previously identified are conserved in both $C$. elegans $\mathrm{MDH}-1$ and $\mathrm{MDH}-2(22-25,51,53)$. The active site includes (using the $\mathrm{MDH} 1$ amino acid numbering in Figure 1) Asn130, His186 (His176 in MDH2), Asp158, and Arg161 as well as Arg91 and Arg97 in the mobile loop that closes over the active site. In MDH1, the adenine ring of NADH binds to Leu40, lle42, Met45, Thr9, Gly10, Ala12, and Gly13 in a hydrophobic pocket. In MDH1 only, Glu73 hydrogen bonds to N6A of adenine. In E. coli MDH, Tyr33, Ile35, Ala77, Ile97, and Leu101 form the hydrophobic adenine binding pocket, and these residues surround the adenine ring in the unpublished human MDH2 structure (4WLU, data not shown). There are hydrogen bonds between the NADH pyrophosphate and GIn14 and Ser240 (neither conserved in MDH2) as well as the backbone of residues of Gln14 (Gly11 in MDH2) and lle15. Asn130 makes hydrogen bonds to the nicotinamide ribose hydroxyl groups, and Asp41 hydrogen bonds to the hydroxyl groups in the adenine ribose. In MDH1, the residues forming a binding site for the nicotinamide ring include Ile15, Val128, Leu154, Leu157, and Ala245. In MDH2, the backbone oxygen of lle117 hydrogen bonds with the nicotinamide carboxyamide group.

Numerous studies have shown that mitochondrial MDH2 enzymes interact with other proteins to channel substrates between enzymes (54-58). For example, the interaction between beef heart MDH2 and citrate synthase (CS) involved amino acids surrounding the $\mathrm{MDH} 2$ active site opening (58), which are nearly all conserved in C. elegans MDH-2, S. scrofa MDH2 and human MDH2.

\section{MDH-1 and MDH-2 Purifications}

The recombinant $\mathrm{MDH}-1$ and $\mathrm{MDH}-2$ enzymes were overexpressed in $E$. coli as fusion proteins with a self-cleaving intein and a chitin binding domain (CBD). The $\mathrm{MDH}-1-\mathrm{CBD}$ and MDH-2-CBD fusion proteins were purified using chitin resin, and the CBD tag was removed from the enzymes using intein cleavage induced by DTT addition. The purification of $\mathrm{MDH}-2$ is shown in Figure 2, and the purification of $\mathrm{MDH}-1$ followed a similar procedure (see the Experimental section and supporting Figure S1). The final recombinant $\mathrm{MDH}-1$ preparation is shown in Figure $3 \mathrm{~B}$, lanes 8 and 10 , and the final recombinant $\mathrm{MDH}-2$ sample is shown in 
Figure 1, lanes 7-10, Figure 2A, lane 5, and Figure 2B, lane 6. The predicted molecular weights for the recombinant $\mathrm{MDH}-1$ and $\mathrm{MDH}-2$ enzymes were 35.9 $\mathrm{kDa}$ and $33.3 \mathrm{kDa}$, respectively. The molecular weights based on the size standards in the SDS-PAGE gel in Figure 2 were $33+/-3 \mathrm{kDa}$ and $31+/-2 \mathrm{kDa}$ (95\% confidence intervals) for $\mathrm{MDH}-1$ and $\mathrm{MDH}-2$, respectively.

The endogenous $\mathrm{MDH}-1$ and $\mathrm{MDH}-2$ enzymes were purified from a $C$. elegans sample that contained worms of various ages. The theoretical pl values for $\mathrm{MDH}-1$ and $\mathrm{MDH}-2$ (after signal sequence cleavage) were 6.6 and 9.1 , respectively. The two proteins were separated using DEAE ion exchange, and then MDH-2 was further purified using a Blue Sepharose column (Figure 3B). The purification process is shown in Table 1.

Table 1. Purification table for endogenous MDH-1 and MDH-2

\begin{tabular}{|l|l|l|l|l|l|}
\hline Sample & $\begin{array}{l}\text { Total Protein } \\
(\mathrm{mg})\end{array}$ & $\begin{array}{l}\text { Total Units } \\
(\mu \mathrm{mol} / \mathrm{min})\end{array}$ & $\begin{array}{l}\text { Specific } \\
\text { Activity }\end{array}$ & $\begin{array}{l}\text { Yield } \\
(\%)\end{array}$ & $\begin{array}{l}\text { Purification } \\
\text { Level }\end{array}$ \\
\hline Clarified Worm Lysate & $3.9 \pm 0.2^{1}$ & $13 \pm 1$ & $\begin{array}{l}3.3 \pm \\
0.3\end{array}$ & 100 & 1 \\
\hline $\begin{array}{l}\text { Gel Filtration Samples } \\
\text { (with MDH-1 and MDH-2) }\end{array}$ & $1.2 \pm 0.2$ & $6.63 \pm 0.2$ & $\begin{array}{l}5.4 \pm \\
0.8\end{array}$ & 52 & 1.6 \\
\hline $\begin{array}{l}\text { dialyzed DEAE fractions } \\
\text { (with MDH-1) }\end{array}$ & $0.06 \pm 0.01$ & $1.6 \pm 0.1$ & $25 \pm 5$ & 12.6 & 7.6 \\
\hline $\begin{array}{l}\text { DEAE Flow-through (with } \\
\text { MDH-2) }\end{array}$ & $0.56 \pm 0.02$ & $1.11 \pm 0.04$ & $\begin{array}{l}2.0 \pm \\
0.1\end{array}$ & 8.7 & $0.6^{2}$ \\
\hline $\begin{array}{l}\text { Blue Sepharose fractions } \\
\text { (with MDH-2) }\end{array}$ & $\begin{array}{l}0.00062 \pm \\
0.00008\end{array}$ & $\begin{array}{l}0.010 \pm \\
0.001\end{array}$ & $21 \pm 3$ & 0.1 & 6.4 \\
\hline
\end{tabular}

${ }^{1}$ Standard errors are shown.

${ }^{2}$ This value is less than 1.0 because the total number of units in the worm lysate included the activity of both $\mathrm{MDH}-1$ and $\mathrm{MDH}-2$. This DEAE flow-through sample only contained activity from $\mathrm{MDH}-2$.

Samples from the endogenous protein purification were run on SDS-PAGE gels next to the recombinant proteins, and there were bands of the expected size in each endogenous sample. The final preparation of endogenous $\mathrm{MDH}-1$ contained about 6 proteins, and the band at the expected size for $\mathrm{MDH}-1$ was the most intense band (Figure 2B, lane 9). The final preparation of $\mathrm{MDH}-2$ contained about 4 proteins, and the band at the expected size for $\mathrm{MDH}-2$ was less intense than some of the other bands (Figure 2B, lane 5). The predicted molecular weights for endogenous $\mathrm{MDH}-1$ and $\mathrm{MDH}-2$ were $35.8 \mathrm{kDa}$ and $32.7 \mathrm{kDa}$. The molecular weights based on the size standards in the SDS-PAGE gel in Figure 
2B were $33+/-3 \mathrm{kDa}$ and $30+/-2 \mathrm{kDa}$ (95\% confidence intervals) for MDH-1 and $\mathrm{MDH}-2$, respectively.

Based on the units $(\mathrm{U}, \mu \mathrm{mol} / \mathrm{min})$ of enzyme activity of the endogenous $\mathrm{MDH}-1$ and $\mathrm{MDH}-2$ samples used for enzyme kinetics (Table 1), the C. elegans sample contained slightly more MDH-1 activity $(1.6 \mathrm{U})$ than $\mathrm{MDH}-2$ activity $(1.1 \mathrm{U})$. This is almost the same ratio (1.5) of MDH activity in the cytoplasmic fraction compared to the mitochondrial fraction from adult $C$. elegans measured in a previous study (19). The specific activities of the final endogenous MDH-1 and $\mathrm{MDH}-2$ samples were similar (Table 1), but much more of the MDH-2 was lost during the purification because the SDS-PAGE sample (Figure 2B, lane 5) went through an extra Blue Sepharose column and ultrafiltration step.

\section{Enzyme Kinetics}

Steady-state enzyme kinetics measurements were performed with the purified endogenous and recombinant $\mathrm{MDH}-1$ and $\mathrm{MDH}-2$ enzymes and analyzed using the Michaelis-Menten equation $(59,60)$. Since the forward $\mathrm{MDH}$ reaction is energetically unfavorable at neutral $\mathrm{pH}$, the reverse reaction is usually studied in vitro $(2,61)$. The $\mathrm{pH}$-dependence of $\mathrm{MDH}-2$ activity was tested from $\mathrm{pH} 4-11$ (see supporting Figure S2), and the enzyme activity was high between $\mathrm{pH} 6-8.5$ in phosphate and Tris- $\mathrm{HCl}$ buffers. Figures $4 \mathrm{~A}$ and $4 \mathrm{~B}$ show the enzyme kinetics results when oxaloacetate was varied, and Figure $4 \mathrm{C}$ shows the results for the recombinant enzymes when NADH was varied. The $K_{\mathrm{M}}$ and $\mathrm{V}_{\max }$ values are shown in Table 2. Blank samples containing all of the reaction components except oxaloacetate were tested for every enzyme preparation, and the rate of change of the absorbance at $340 \mathrm{~nm}$ was at least 10-fold lower than the rates measured at the lowest oxaloacetate concentrations.

\section{Table 2. Summary of Michaelis-Menten values}

\begin{tabular}{|c|c|c|c|c|}
\hline Enzyme & $K_{M}, \mu M$ & $\begin{array}{c}K_{M} \text { std } \\
\text { error }\end{array}$ & $\begin{array}{c}\text { Vmax, } \\
\mu M / m i n\end{array}$ & $\begin{array}{c}\text { Vmax std } \\
\text { error }\end{array}$ \\
\hline Endo. MDH-1 & 50 & 4 & 26.5 & 0.8 \\
\hline Recomb. MDH-1 & 54 & 4 & 32 & 1.0 \\
\hline Endo. MDH-2 & 42 & 2 & 22.1 & 0.5 \\
\hline Recomb. MDH-2 & 52 & 4 & 66 & 2 \\
\hline Recomb. MDH-1 & 61 & 6 & 40 & 2 \\
\hline Recomb. MDH-2 & 107 & 5 & 113 & 3 \\
\hline
\end{tabular}


The $K_{\mathrm{M}}$ values for recombinant and endogenous $\mathrm{MDH}-1$ were quite similar: $54 \pm$ $4 \mu \mathrm{M}$ and $50 \pm 4 \mu \mathrm{M}$, respectively, with the standard errors shown. The $K_{\mathrm{M}}$ values for recombinant and endogenous $\mathrm{MDH}-2$ varied more: $52 \pm 4 \mu \mathrm{M}$ and $42 \pm 2 \mu \mathrm{M}$, respectively. This difference may be because the recombinant $\mathrm{MDH}-2$ enzyme had a few extra amino acids on the $\mathrm{N}$ - and $\mathrm{C}$-termini (see Experimental Methods). The $K_{\mathrm{M}}$ values for NADH were $61 \pm 6 \mu \mathrm{M}$ and $107 \pm 5 \mu \mathrm{M}$ for recombinant $\mathrm{MDH}-1$ and $\mathrm{MDH}-2$, respectively. The $K_{\mathrm{M}}$ values for $\mathrm{NADH}$ for the endogenous enzymes were not determined.

We attempted to do enzyme kinetics with malate and $\mathrm{NAD}^{+}$with recombinant $\mathrm{MDH}-1$ and MDH-2 under a variety of reaction conditions. Specifically, we tried higher concentrations of each reagent and higher $\mathrm{pH}$ values, because these conditions have worked for some MDH enzymes $(5,6,62)$. However, we were not able to observe any enzyme activity with malate and $N A D^{+}$under any of the conditions we tried (data not shown).

The protein concentrations and the $\mathrm{V}_{\max }$ values when $\mathrm{NADH}$ was varied were used to calculate the specific activities and $k_{\text {cat }}$ values for the recombinant enzyme preparations (Table 3). As shown in the recombinant $\mathrm{MDH}-1$ and $\mathrm{MDH}-2$ purification gels (Figure 1 and supporting Figure S1), the MDH-1 enzyme expressed to a higher level in $E$. coli. The final specific activity of recombinant $\mathrm{MDH}-2$ was slightly higher than that for $\mathrm{MDH}-1$ (Table 3 ). This may be because the $\mathrm{MDH}-1$ preparation contained a low level of contaminating MDH-1-CBD fusion protein and cleaved CBD (see supporting Figure S1).

The protein concentrations and the reaction rates measured at $150 \mu \mathrm{M}$ oxaloacetate and $100 \mu \mathrm{M}$ NADH were used to calculate the specific activities of the endogenous enzymes (Table 1). The enzyme kinetics for endogenous MDH-1 was measured using the DEAE fractions, shown in lanes 8 and 9 in Figure $3 \mathrm{~A}$ and lane 9 of Figure 3B. The enzyme kinetics for endogenous MDH-2 was measured using the DEAE flow-through fractions, such as those shown in lanes 3 and 4 in Figure 3A. The MDH-2 sample after the Blue Sepharose column that is shown in Figure $3 \mathrm{~B}$, lane 5 was used to determine a specific activity of 21 $\mathrm{U} / \mathrm{mg}$, compared to $25 \mathrm{U} / \mathrm{mg}$ for $\mathrm{MDH}-1$ (Table 1 ). These results are fairly consistent with the SDS-PAGE gels (Figure 3B), because the MDH-1 band is more intense compared to the contaminating protein bands, while the $\mathrm{MDH}-2$ band is faint compared to the contaminants. 
Table 3. Specific Activities and $k_{\text {cat }}$ values of recombinant MDH-1 and MDH-2

\begin{tabular}{|l|l|l|l|l|}
\hline Sample & $\begin{array}{l}\text { Total Protein } \\
(\mathrm{mg})\end{array}$ & Total Units & $\begin{array}{l}\text { Specific } \\
\text { Activity, } \\
\text { U/mg }\end{array}$ & $\mathrm{k}_{\text {cat }}, \mathrm{s}^{-1}$ \\
\hline${\mathrm{MDH}-1^{\mathrm{a}}}^{\mathrm{a}}$ & $2.01 \pm 0.07^{\mathrm{c}}$ & $1190 \pm 57$ & $590 \pm 35$ & $350 \pm 21$ \\
\hline $\mathrm{MDH}^{\mathrm{b}}{ }^{\mathrm{b}}$ & $0.27 \pm 0.01$ & $227 \pm 6$ & $828 \pm 41$ & $460 \pm 23$ \\
\hline
\end{tabular}

a Measured using the combined fractions 1 and 2 for $\mathrm{MDH}-1$ and calculated using the $\mathrm{V}_{\text {max }}$ when NADH was varied.

bMeasured using the combined fractions 1 and 2 for MDH-2 and calculated using the $\mathrm{V}_{\max }$ when NADH was varied.

'Standard errors are shown.

\section{MDH-1 and MDH-2 Thermostability}

During our experiments, we noticed that $\mathrm{MDH}-1$ was very stable, even when left at room temperature for a couple days. To test whether recombinant $\mathrm{MDH}-1$ and $\mathrm{MDH}-2$ have different temperature optima, we measured the temperature-dependence of the activity of each enzyme (Figure 5). The optimum temperature of $\mathrm{MDH}-1$ was about $40{ }^{\circ} \mathrm{C}$, while the optimum for $\mathrm{MDH}-2$ was about $35^{\circ} \mathrm{C}$. To determine the thermostability of the enzymes without any interference from the temperature-sensitivity of the substrates, we incubated the recombinant enzymes at $55^{\circ} \mathrm{C}$ for different lengths of time and then measured the residual enzyme activity at $24{ }^{\circ} \mathrm{C}$ (Figure 6). This experiment showed a clear difference in the thermostabilities of $\mathrm{MDH}-1$ and $\mathrm{MDH}-2 . \mathrm{MDH}-1$ maintained its activity for about $10 \mathrm{~min}$ at $55^{\circ} \mathrm{C}$, while $\mathrm{MDH}-2$ lost its activity in about $1 \mathrm{~min}$. The thermostability of $\mathrm{MDH}-1$ was interesting because $C$. elegans have an optimum growing temperature in the laboratory of $20^{\circ} \mathrm{C}$, and temperatures above $28^{\circ} \mathrm{C}$ can cause detrimental effects such as sterility $(63,64)$.

\section{Protein structure modeling}

To investigate structural features that could explain the increased thermal stability of $\mathrm{MDH}-1$ compared to $\mathrm{MDH}-2$, we did protein structure homology modeling because the crystal structures of $C$. elegans $\mathrm{MDH}-1$ and $\mathrm{MDH}-2$ have not been determined. The MDH-1 and MDH-2 sequences were submitted to SWISS-MODEL (39), and the predicted structures were built with the crystal structures 1BMD.1.A (25) and 2DFD.1.A (unpublished structure from the Structural Genomics Consortium) as the templates, respectively. The models had 
GMQE and QMEAN scores (41) of 0.79 and -0.62 , respectively, for $\mathrm{MDH}-1$ and 0.78 and -0.04 , respectively, for $\mathrm{MDH}-2$. The $\mathrm{MDH}-1$ model was refined by minimizing the free energy using the YASARA energy minimization server (42). The z-scores for the modeled $\mathrm{MDH}-1$ and $\mathrm{MDH}-2$ structures were -9.32 and -10.69 , respectively. The bond and rotamer angles were checked using MolProbity $(45,46)$. The MDH-1 model had 95\% favored rotamers, $98 \%$ favored Ramachandran angles, and no Ramachandran outliers. The MDH-2 model had $97 \%$ favored rotamers, $97 \%$ favored Ramachandran angles, and no outliers. Both models passed the Verify 3D assessment (47-49). All of these results indicated that both model structures were of high quality. (The raw output from these tests are shown in supplementary Figures S3-S5, and the PDB files of the $\mathrm{MDH}-1$ and $\mathrm{MDH}-2$ protein structure models are posted with the supplementary information.)

Previous studies have found that more stable MDH enzymes contained more intersubunit hydrogen bonds and ion pairs in comparison to less stable ones. In addition, salt bridges (hydrogen-bonded ion pairs) may contribute more to protein stability at high temperatures $(25,65)$. Therefore, we searched for predicted hydrogen bonds between the subunits of both modeled MDH-1 and MDH-2 structures and focused on the salt bridges (Tables 4 and 6). We found that $\mathrm{MDH}-1$ had more predicted ionic interactions between the two subunits than $S$. scrofa MDH1 but fewer interactions than the thermostabile T. thermophilus $\mathrm{MDH}$. $\mathrm{MDH}-1$ had predicted salt bridges between Asp25 and Arg22, Asp25 and Lys248 (Figure 7A), and Glu50 and Lys 236 (Figure 7D). S. scrofa MDH1 doesn't form these salt bridges because it has different amino acids at these locations. Specifically, it has Asn25 \& Ser22 (Figure 7B) and Asp50 \& Ala236 (Figure 7E) in the corresponding positions. Figure 7E also illustrates a salt bridge in S. scrofa $\mathrm{MDH} 1$ that is also found in MDH-1 between Glu55 and Arg237 (see Table 4), but this bond is not visible in Figure 7D. T. thermophilus MDH has a different, novel salt bridge between Arg22 and Glu27 (Figure 7C), and it has an Ala236, so there are no intersubunit hydrogen bonds in the view shown in Figure 7F. T.

thermophilus MDH also has an interdomain salt bridge (Arg149-Glu276) that may contribute to its stability, and this interaction is not found in S. scrofa MDH1 (25). $\mathrm{MDH}-1$ has Lys 149 and Ser276, but there is a predicted hydrogen bond between NZ Lys149 and OD2 Asp273 in subunit B with a distance of $2.91 \AA$ between the donor and acceptor atoms. In subunit $A$, these two atoms are $4.15 \AA$ apart, and Asp273 makes hydrogen bonds with Ser276 instead. The structures of the two subunits in S. scrofa MDH1 and MDH2 are quite similar to each other but not identical $(22,23)$, and this is the source of the disparity between the hydrogen bond lengths in the two subunits. 
Table 4. Intersubunit hydrogen bonds in MDH-1 and homologous MDH enzymes

\begin{tabular}{|c|c|c|c|c|}
\hline H-bond & $\begin{array}{l}\mathrm{MDH}-1 \\
\text { subunit } \mathrm{A} \text { to } \\
\mathrm{B}^{\mathrm{a}}\end{array}$ & $\begin{array}{l}\mathrm{MDH}-1 \\
\text { subunit } \mathrm{B} \\
\text { to } \mathrm{A}^{\mathrm{a}}\end{array}$ & $\begin{array}{l}T . \\
\text { thermophilus }\end{array}$ & $\begin{array}{l}\text { S. scrofa } \\
\text { MDH } 1^{\mathrm{b}}\end{array}$ \\
\hline \multicolumn{5}{|c|}{ Hydrogen bonds between 2 charged amino acids. } \\
\hline 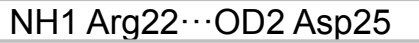 & $4.37^{*}$ & 2.85 & & \\
\hline $\mathrm{NH} 2$ Arg22 $\cdots$ OD2 Asp25 & $6.28^{*}$ & 2.99 & & \\
\hline 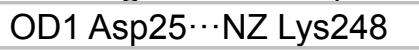 & 2.91 & $4.07^{*}$ & & \\
\hline 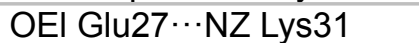 & & & c & \\
\hline 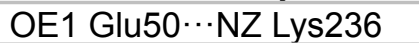 & 2.83 & $4.21^{*}$ & & \\
\hline 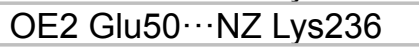 & 3.46 & $4.02^{*}$ & & \\
\hline 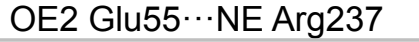 & 2.84 & 2.86 & & d \\
\hline 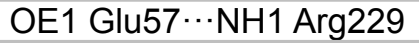 & & & c & \\
\hline 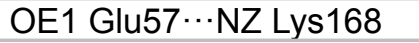 & & & c & \\
\hline OD1 Asp58 $\cdots \mathrm{NH} 1$ Arg229 & 2.88 & 3.03 & c & d \\
\hline 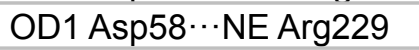 & 3.00 & 2.86 & & \\
\hline OD2 Asp58 $\cdots$ NE Arg229 & 2.98 & 3.6 & c & d \\
\hline 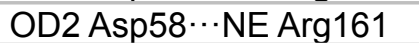 & 3.50 & 2.84 & c & d \\
\hline \multicolumn{5}{|c|}{ Hydrogen bonds involving 0 or 1 charged amino acid } \\
\hline OH Tyr17 $\cdots$ N Met243 & 2.96 & 3.2 & (N Ala243)c & d \\
\hline OH Tyr17 $\cdots$ N Ala242 & $3.37^{*}$ & $3.4^{*}$ & c & d \\
\hline $\mathrm{OH}$ Tyr17 $\cdots \mathrm{NH} 2$ Arg237 & $3.03^{*}$ & $3.80^{*}$ & c & d \\
\hline O Met54 $\cdots \mathrm{NH} 1 \mathrm{Arg} 229$ & & & c & d \\
\hline 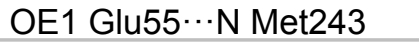 & $2.97^{*}$ & 3.05 & & \\
\hline 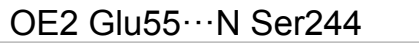 & 2.96 & 3.37 & c & d \\
\hline 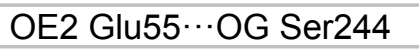 & $3.39^{*}$ & $3.93^{*}$ & c & d \\
\hline 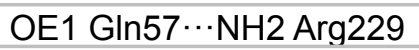 & 2.96 & 2.90 & & d \\
\hline 0 Cys $59 \cdots$ NZ Lys 247 & $4.76^{*}$ & $3.59^{*}$ & $\begin{array}{l}\text { (ND2 } \\
\text { Asn247)c }\end{array}$ & d \\
\hline
\end{tabular}

* The MDH-1 model predicts a poor alignment for a hydrogen bond.

a. Distance measured in PyMOL between donor and acceptor in $\AA$

b. Human MDH1 has the same sequence as the $S$. scrofa protein at all the amino acids listed in this table.

c. Kelly et al. $1993(25)$

d. Birktoft et al. 1989 (22)

In addition to ionic interactions, other protein structural features can contribute to protein stability, and different enzymes use different strategies to stabilize their structures (66-68). For example, some thermostable MDH enzymes have a high percentage of alanine residues and aromatic residues (69). Studies of other proteins, such as T4 lysozyme and alcohol dehydrogenase, have found that more thermostable proteins have more prolines and fewer glycines $(70,71)$. The T. thermophilus MDH sequence follows some of these trends (Table 5). $T$. 
thermophilus MDH has a large percentage of Ala and Pro residues, an intermediate percentage of Gly residues, and the same percentage of aromatic residues as S. scrofa MDH1. MDH-1 has more Ala and Phe residues but also more Gly residues and the same number of Pro residues compared to $S$. scrofa $\mathrm{MDH} 1$. Therefore, $\mathrm{MDH}-1$ has some but not all of the stabilizing amino acid characteristics found in other thermostable proteins. T. thermophilus MDH has fewer Ser and Thr residues than the other two proteins. Another study found that thermostabile MDH enzymes had larger volumes than mesophilic enzymes (66). Using the MDH-1 model and the crystal structures of S. scrofa MDH1 and T. thermophilus $\mathrm{MDH}$, we measured volumes of $80,600,83,600$, and $81,200 \AA^{3}$, respectively. Therefore, these proteins don't follow the predicted trend in volumes since S. scrofa had the largest volume.

\section{Table 5. Amino acid percentage in MDH-1 and homologous MDH enzymes}

\begin{tabular}{|c|c|c|c|c|}
\hline Amino Acid & MDH-1 & S. s. MDH1 & $\begin{array}{c}\text { T. } t \\
\text { MDH }\end{array}$ \\
\hline Ala & $13.1^{*}$ & 9.3 & 14.7 \\
\hline Gly & 8.9 & 6.6 & 8.3 \\
\hline Pro & 3.9 & 3.9 & 4.9 \\
\hline Phe & 5.1 & 3.3 & 3.1 \\
\hline Trp & 0.9 & 1.2 & 1.2 \\
\hline Tyr & 1.8 & 2.1 & 2.1 \\
\hline Ser + Thr & 11.3 & 11.7 & 7.0 \\
\hline
\end{tabular}

*The percentage of the amino acid(s) listed compared to the total number of amino acids is shown for each protein. 
When we searched for predicted ionic interactions in the $\mathrm{MDH}-2$ model, we found fewer interactions than in S. scrofa MDH2 (Table 6). We also used the unpublished human MDH2 structure (4WLU) to check for hydrogen bonds. Gleason et al. (1993) mentioned two intersubunit hydrogen bonds in S. scrofa MDH2, between Glu48 and Arg233 and between Asp43 and Lys217 (23). The interaction between Asp43 and Lys217 appeared to be conserved in all three proteins. The Glu48-Arg233 interaction was conserved in human MDH2, but the bond length in $\mathrm{MDH}-1$ was longer because $\mathrm{MDH}-2$ has an Asp48. Our analysis of S. scrofa MDH2 predicted another hydrogen bond between Arg50 and Asp164, which was not conserved in $\mathrm{MDH}-2$, and it probably doesn't form in human $\mathrm{MDH} 2$ because the human protein has a Lys50, and its terminal amino group is quite distant from Asp164.

Table 6. Inter-subunit hydrogen bonds in MDH-2 and homologous MDH enzymes $^{a}$

\begin{tabular}{|c|c|c|c|c|c|c|}
\hline \multirow[t]{2}{*}{ Hydrogen bond } & \multicolumn{2}{|c|}{ MDH-2 } & \multicolumn{2}{|c|}{ S. scrofa MDH2 } & \multicolumn{2}{|c|}{ human $\mathrm{MDH} 2$} \\
\hline & $A$ to $B$ & $B$ to $A$ & $A$ to $B$ & $B$ to $A$ & $A$ to $B$ & $B$ to $A$ \\
\hline $\begin{array}{l}\text { OE2 Glu48 } \cdots \mathrm{NH} 1 \\
\text { Arg233 }\end{array}$ & $\begin{array}{l}3.52 \\
\left(A_{s p}\right)\end{array}$ & $\begin{array}{l}3.65^{*} \\
\left(\text { Asp }^{b}\right)\end{array}$ & $2.72^{\mathrm{c}}$ & $2.87^{c}$ & 2.89 & 2.92 \\
\hline $\begin{array}{l}\text { NH1 Arg50 …OD1 } \\
\text { Asp164 }\end{array}$ & - & - & 2.90 & 2.75 & $\begin{array}{l}6.32^{*} \\
\left(\text { Lys }^{d}\right)\end{array}$ & $\begin{array}{l}4.80^{*} \\
\left(\text { Lys }^{d}\right)\end{array}$ \\
\hline $\begin{array}{l}\text { OD2 Asp } 43 \cdots \mathrm{NZ} \\
\text { Lys217 }\end{array}$ & 2.70 & 2.58 & $2.82^{\mathrm{c}}$ & $2.94^{c}$ & 3.01 & 3.44 \\
\hline
\end{tabular}

* Model predicts a poor alignment for a hydrogen bond.

a. Distance between donor and acceptor atoms in the two subunits in $\AA$

b. MDH-2 has an Asp instead of a Glu at position 48.

c. Gleason et al. 1993 (23)

d. Human MDH2 has a Lys instead of an Arg at position 50.

\section{Discussion}

We performed enzyme kinetics, thermostability, and protein structure analyses of C. elegans MDH-1 and MDH-2. These enzymes have not been characterized before, even though they are central metabolic enzymes in an important experimental organism. C. elegans is not a thermophilic organism, but it can withstand a variety of environmental conditions. These conditions could cause selection pressure on the $C$. elegans metabolic enzymes. 


\section{MDH-1 and MDH-2 thermal stability}

A larger number of salt bridges between subunits has been shown previously to increase the thermal stability of enzymes such as glutamate dehydrogenase and $\operatorname{MDH}(25,69,72,73)$. We found that homology modeling of $C$. elegans MDH-1 predicted more intersubunit salt bridges and ion pairs compared to S. scrofa MDH1 but fewer compared to T. thermophilus MDH (Table 4). If these interactions contributed to the thermostability of $\mathrm{MDH}-1$, we would expect $\mathrm{MDH}-1$ to be more thermostabile than S. scrofa MDH1 but less thermostable than $T$. thermophilus $\mathrm{MDH}$. We found that $C$. elegans $\mathrm{MDH}-1$ lost $50 \%$ of its activity when incubated at $55^{\circ} \mathrm{C}$ for about $17 \mathrm{~min}$ in $0.5 \mathrm{mM} \mathrm{NADH}$ and $50 \mathrm{mM}$ Tris, pH 7.5 (Figure 6). Trejo et al. (2001) measured a half time of inactivation for His-tagged S. scrofa MDH1 of $13 \mathrm{~min}$ at $55^{\circ} \mathrm{C}$ in $50 \mathrm{mM}$ sodium phosphate buffer, pH 7.4 (73). A previous study measured a half time of inactivation of endogenous S. scrofa MDH1 of $20 \mathrm{~min}$ at $55^{\circ} \mathrm{C}$ in $0.1 \mathrm{M}$ phosphate buffer, pH 7.4 (74). T. thermophilus $\mathrm{MDH}$ remained fully active after incubation at $90{ }^{\circ} \mathrm{C}$ for $60 \mathrm{~min}$ in 20-33 $\mathrm{mM}$ potassium phosphate, $\mathrm{pH} 7.0(75,76)$. Another study measured a half time of inactivation of $T$. thermophilus $\mathrm{MDH}$ of $34 \mathrm{~min}$ at $90{ }^{\circ} \mathrm{C}$ in $20 \mathrm{mM}$ phosphate buffer, $\mathrm{pH} 7.4$ (77). Therefore, it appears that MDH-1 had a similar thermostability as $\mathrm{S}$. scrofa $\mathrm{MDH} 1$, and $\mathrm{MDH}-1$ was significantly less thermostable than T. thermophilus MDH. Perhaps the additional intersubunit ionic interactions in $\mathrm{C}$. elegans $\mathrm{MDH}-1$ optimize enzyme activity in other conditions besides high temperatures.

We observed the highest enzyme activity for $\mathrm{MDH}-1$ and $\mathrm{MDH}-2$ at 40 and $35^{\circ} \mathrm{C}$, respectively (Figure 5). Recombinant His-tagged S. scrofa MDH1 had maximum activity at $60^{\circ} \mathrm{C}(73)$. This difference seems reasonable since $C$. elegans have an optimum growing temperature around $20^{\circ} \mathrm{C}$, while mammals typically maintain a $37^{\circ} \mathrm{C}$ temperature. Even though $\mathrm{MDH}-1$ had lower activity at reaction temperatures above $40^{\circ} \mathrm{C}$, the enzyme could retain activity for about $10 \mathrm{~min}$. when it was heated to $55-57^{\circ} \mathrm{C}$ and then quickly cooled and assayed at $24^{\circ} \mathrm{C}$ (Figure 6). This suggests that the denaturation of $\mathrm{MDH}-1$ may be reversible up to a point if the enzyme lost activity in assays performed above $40{ }^{\circ} \mathrm{C}$ because it started to denature. The ability to refold is a feature of some thermostable enzymes and may be advantageous for maintaining activity under adverse conditions (66). If an enzyme refolds incorrectly, a buried, charged residue mis-aligned from its binding partner could be very unstable. These higher energy folding intermediates may facilitate native enzyme refolding by preventing enzymes with numerous buried salt bridges, like $\mathrm{MDH}-1$, from being trapped in a low-energy, non-native conformation (65). 
We measured a rate of inactivation of $\mathrm{MDH}-2$ of $2.85 \mathrm{~min}^{-1}$ (which corresponds to a $\mathrm{t}_{1 / 2}$ of $0.24 \mathrm{~min}$ ) under the same conditions as those used for $\mathrm{MDH}-1$ (Figure 6), and homology modeling predicted fewer intersubunit ion pairs compared to $S$. scrofa MDH2 (Table 6). One study reported a $t_{1 / 2}$ of inactivation of $S$. scrofa $\mathrm{MDH} 2$ at $60{ }^{\circ} \mathrm{C}$ in $20 \mathrm{mM}$ phosphate buffer, pH 7.4, of $1.8 \mathrm{~min}$ (77), suggesting that $\mathrm{S}$. scrofa $\mathrm{MDH} 2$ was more stable than $\mathrm{MDH}-2$ since $\mathrm{MDH}-2$ lost activity faster at a lower temperature. These results are consistent with the difference in intersubunit interactions in the two enzymes. In addition, based on our analysis of the human MDH2 structure (Table 6), we would predict that it is intermediate in stability between MDH-2 and S. scrofa MDH2.

$\mathrm{MDH}-2$ may be structurally less stable because MDH2 enzymes have been found to bind to fumarase and citrate synthase in the mitochondria (reviewed in $(78,79))$. This facilitates substrate channeling through the citric acid cycle because the forward reaction of malate dehydrogenase is thermodynamically unfavorable while the citrate synthase reaction is favorable (61). The binding between $S$. scrofa MDH2 and citrate synthase was found to be specific but transient (80). When we purified endogenous $\mathrm{MDH}-2$, it is likely that $\mathrm{MDH}-2$ was separated from fumarase and citrate synthase. The interactions between MDH-2 and its binding partners may stabilize the structure of this protein complex so that it can function even if the separate enzymes are not as stable.

The stability differences between $\mathrm{MDH}-1$ and $\mathrm{MDH}-2$ may partly be the result of their different phylogenetic origins. Numerous studies have shown that MDH enzymes cluster into three clades $(1,81,82)$, and two of these clades are evident in Figure 1. The sequences of mitochondrial $\mathrm{MDH}$ enzymes have a high sequence similarity to some eubacterial MDH enzymes, consistent with the theory of a bacterial origin of mitochondria $(83,84)$. The ancestors of eukaryotic cells are still an active area of research, but recently archaeal genomes have been sequenced that contain classes of proteins considered to be eukaryotic signature proteins, such as the phylum Lokiarchaeota $(85,86)$. However, this second clade of archaeal MDH enzymes are more similar to lactate dehydrogenases than to MDH enzymes $(1,81,82)$. The third clade of MDH enzymes include other eubacterial enzymes, such as $T$. thermophilus, and cytoplasmic MDH1 enzymes, and these are highly diverged from the mitochondrial MDH2 enzymes $(2,76)$ Perhaps the bacterial ancestors of cytoplasmic MDH were more stable. Interestingly, additional thermostable bacterial $\mathrm{MDH}$ enzymes have been found that were more similar to cytoplasmic $\mathrm{MDH}$ than mitochondrial MDH, such as those from Streptomyces coelicolor A3(2) and Streptomyces avermitilis MA-4680 $(87,88)$. 


\section{MDH-1 and MDH-2 functions in C. elegans dauer larvae}

In our analysis of the intersubunit ionic interactions for $\mathrm{MDH}-1$ and $\mathrm{MDH}-2$, we found that $\mathrm{MDH}-1$ had more intersubunit interactions compared to the homologous mammalian enzymes, while MDH-2 had fewer. This suggested that there were differences in the selective pressures against each enzyme. We hypothesized that one reason for the increased stability of $\mathrm{MDH}-1$ was because it was important for metabolism in dauer larvae, while the requirement for $\mathrm{MDH}-2$ was reduced. There is support for this in the literature. Dauer larvae can be produced naturally, such as by increasing the $C$. elegans density and reducing food availability, or artificially using mutant strains. The daf-2 strains have mutations in an insulin receptor, and different strains form dauer larvae either constitutively or in a temperature-dependent manner $(15,89)$. Strains with daf-2 mutations have an extended lifespan (90), and they have a similar, but not identical, metabolic signature as dauer worms $(16,91)$. Whole genome microarray experiments showed that the $m d h-1$ gene was overexpressed in dauer larvae while $m d h-2$ was underexpressed $(16,21,92)$. Another study used serial analysis of gene expression and found that $m d h-2$ was underexpressed in dauer larvae (93). Fuchs et al. (2010) reported an increase in expression of $m d h-1$ in daf-2 dauer worms (91). The protein MDH-1 was more abundant in daf-2 worms compared to control worms $(94,95)$ and in daf-2 dauers grown at 25 ${ }^{\circ} \mathrm{C}$ compared to daf-2 larvae grown at the permissive temperature (96). However, Depuydt et al. (2014) found that levels of MDH-2 protein were slightly elevated in daf-2 worms (94). The fact that MDH-1 expression was elevated in dauer worms suggests that it plays an important role in this life cycle stage.

$\mathrm{MDH}-1$ expression is likely elevated in dauer larvae because the metabolic processes occurring in dauers depend on its activity. There are three main pathways that are relevant, and they have each been emphasized in different studies. The first pathway involves the glyoxylate shunt, which is important in dauer larvae since they rely on stored lipids for energy. As discussed above, malate produced in the mitochondria by the glyoxylate shunt bypasses $\mathrm{MDH}-2$ and is exported to the cytoplasm and converted to oxaloacetate by MDH-1. The expression of genes involved in the glyoxylate shunt are up-regulated in dauer larvae $(16,21)$. In daf-2 dauer worms, the main glyoxylase enzyme, ICL-1, is up-regulated when measured by mass spectrometry (96). A study of enzyme activities in protein extracts derived from adult worms or dauer larvae found that the activity of isocitrate dehydrogenase was greatly reduced in dauer larvae compared to adult worms, but the activity of isocitrate lyase was only slightly reduced in dauers, suggesting that a larger fraction of isocitrate was metabolized via the glyoxylate pathway compared to the citric acid cycle in dauer worms (19). 
Therefore, the importance of the glyoxylate shunt in dauer metabolism is well supported.

The second relevant pathway in dauers is gluconeogenesis. Oxaloacetate produced by $\mathrm{MDH}-1$ in the cytoplasm is converted to phosphoenolpyruvate (PEP) by PEP carboxykinase (PEPCK), and PEP can be used for gluconeogenesis. There has been some debate in the literature about how much gluconeogenesis actually occurs in dauer larvae. One would expect gluconeogenesis to occur since dauer larvae do not feed. Also, numerous studies have shown that proteins involved in gluconeogenesis, such as PEPCK, are up-regulated in dauer larvae, and this has been shown using gene expression or protein levels measured by mass spectrometry $(16,21,96)$. However, in a study using enzyme assays in protein extracts, the authors found that PEPCK activity was similar in dauer larvae compared to adult worms, and fructose 1,6-bisphosphatase activity was low in dauers (97). Since fructose 1,6-bisphosphatase is an important regulatory step in gluconeogenesis, the authors argued that it was more likely that PEPCK was functioning in reverse to fix $\mathrm{CO}_{2}$ and form oxaloacetate. In other words, high PEPCK levels did not indicate the predominant direction of the PEPCK reaction. Under specific environmental conditions, such as mild desiccation ( $98 \%$ relative humidity), daf-2 dauer larvae are able to initiate gluconeogenesis to make trehalose, and the amount of trehalose formed depended on the presence of the icl-1 gene, which encodes one of the main glyoxylase shunt enzymes. However, when not exposed to mild desiccation, dauer larvae contained lower levels of trehalose that were similar whether icl-1 was present or not (14). Therefore, dauer larvae were capable of up-regulating gluconeogenesis when necessary, and this required the glyoxylate pathway and would require $\mathrm{MDH}-1$, but dauers did not seem to carry out gluconeogenesis constitutively.

A third metabolic process in dauer worms called malate dismutation can also involve $\mathrm{MDH}-1$. Malate can be generated by PEPCK and $\mathrm{MDH}-1$ in the cytoplasm and transported into the mitochondria $(94,97)$, or malate can be produced by the glyoxylate shunt in the mitochondria. There, malate can be metabolized via malate dismutation, which requires specialized enzymes (see Figure S6 for a diagram). In this process, some of the malate is converted to fumarate by fumarase, while some of the malate is converted to pyruvate via malic enzyme, a process that generates NADH. The NADH provides reducing equivalents to Complex I to reduce rhodoquinone, an electron carrier similar to ubiquinone, which is used by fumarate reductase (an alternative version of Complex II) to convert fumarate to succinate $(98,99)$. A few electrons are transported across the inner mitochondrial membrane by Complex I to generate 
ATP via oxidative phosphorylation, but the final electron acceptor is fumarate rather than oxygen, so dauer worms consume less oxygen $(14,100)$. Interestingly, malate dismutation appears to occur in many long-lived mutant strains of $C$. elegans, and oxaloacetate and malate can extend the lifespan of $C$. elegans $(94,101-104)$. However, the specific processes required for life-span extension are varied, and they are actively discussed in the literature. During malate dismutation, $\mathrm{MDH}-1$ acts in the energetically favorable direction (from oxaloacetate to malate), while $\mathrm{MDH}-2$ is not involved in this pathway.

Other processes occur in dauer larvae to maintain enzyme activity at higher temperatures. For example, in wild-type and daf-2 worms, the presence of exogenous or endogenously produced trehalose increased the thermotolerance of the worms $(105,106)$. Trehalose has also been found to increase the thermal stability of enzymes in vitro (107). In Saccharomyces cerevisiae, trehalose stabilized proteins during heat shock and reduced aggregation of partly unfolded proteins, but trehalose was rapidly degraded after heat shock to allow proteins to refold (108). Similarly, trehalose could stabilize proteins in C. elegans and reduce protein aggregation $(105,109)$. The presence of trehalose could cause greater thermostability of enzymes in dauer larvae and assist with protein refolding. Therefore, multiple mechanisms may allow proteins to function under adverse conditions in dauer larvae.

\section{MDH-1 and MDH-2 functions during favorable growth conditions}

It seems less likely that the differential stability of $\mathrm{MDH}-1$ and $\mathrm{MDH}-2$ result from reactions occurring during favorable, aerobic growth conditions because both $\mathrm{MDH}-1$ and $\mathrm{MDH}-2$ are required. Specifically, both enzymes act in the malate-aspartate shuttle to transport electrons across the inner mitochondrial membrane. Since the inner membrane is impermeable to NAD ${ }^{+}$and $\mathrm{NADH}$, other molecules are used to transport reducing equivalents to the electron transport chain. In this process, NADH from glycolysis is used by $\mathrm{MDH}-1$ to convert oxaloacetate to malate, which is transported across the inner membrane via the 2-oxoglutarate/malate carrier protein, called MISC-1 in C. elegans (110). Inside the mitochondrial matrix, $\mathrm{MDH}-2$ regenerates the $\mathrm{NADH}$. The resulting oxaloacetate can either enter the citric acid cycle or be transaminated to aspartate and then transported back out of the matrix via a calcium-binding mitochondrial carrier protein, which is human SLC25A12 and probably K02F3.2 in $C$. elegans $(111,112)$. This process is sustainable because 2-oxoglutarate is exported out of the matrix by MISC-1, and aspartate is used to transaminate 2-oxoglutarate to glutamic acid in the inner membrane space. This regenerates oxaloacetate in the cytoplasm. Also, glutamic acid can return to the matrix via 
K02F3.2 and be the amino group donor for transaminases. This process requires the activity of both MDH enzymes and both antiporter carrier proteins.

\section{Enzyme Kinetics Results}

Our enzyme kinetics results for $\mathrm{MDH}-1$ and $\mathrm{MDH}-2$ were similar to those found for homologous enzymes. Previous studies have reported $K_{\mathrm{M}}$ values for $S$. scrofa $\mathrm{MDH} 1$ and $\mathrm{MDH} 2$ of $30-35 \mu \mathrm{M}$ and $40 \mu \mathrm{M}$, respectively, under similar reaction conditions and a $\mathrm{k}_{\mathrm{cat}}$ value of $475 \mathrm{~s}^{-1}$ for $\mathrm{S}$. scrofa MDH1 $(73,113)$. Our results were also similar to those found for recombinant cytoplasmic MDH from the tapeworm Taenia solium. This enzyme had a $K_{\mathrm{M}}$ for oxaloacetate and NADH of $44 \mu \mathrm{M}$ and $167 \mu \mathrm{M}$, respectively, and a specific activity of 720 Units/mg protein (6). More divergent results were found for recombinant cytosolic $\mathrm{MDH}$ from the liver fluke Fasciola gigantica. This enzyme had a $K_{\mathrm{M}}$ for oxaloacetate and NADH of $276 \mu \mathrm{M}$ and $141 \mu \mathrm{M}$, respectively (5). Other $\mathrm{MDH}$ enzymes from invertebrates had a wide range of $K_{M}$ and specific activity values, but for most of these studies, the results couldn't be directly compared to our results because the reaction conditions were too different.

The enzyme kinetics constants for $\mathrm{MDH}-1$ and $\mathrm{MDH}-2$ were similar to each other except for the $K_{\mathrm{M}}$ of NADH (Figure 4C). Some researchers have compared the kinetics of $S$. scrofa MDH1 and MDH2. They did not determine $K_{\mathrm{M}}$ values, so their results are not directly comparable to the experiments shown in Figure 4. However, they did do simulations showing that MDH1 had a higher enzymatic activity than $\mathrm{MDH} 2$ at low [NADH] (62), and this is consistent with our measurement of a lower $K_{\mathrm{M}}$ for $\mathrm{NADH}$ for $\mathrm{MDH}-1$ compared to $\mathrm{MDH}-2$ (Figure $4 C$ ). The lower $K_{\mathrm{M}}$ for MDH-1 would also allow it to have more activity at the lower $[\mathrm{NADH}]$ in the cytoplasm compared to the mitochondrial matrix (reviewed in (114)). 


\section{Data availability}

All data are contained within the manuscript and Supporting Information.

\section{Acknowledgements}

We are grateful to Wei Gu, Megan Gautier, Anamica Bedi, Penelope Lindsay, Alexander Strzalkowski, Sanchita Mukherjee, Robert Hincapie, Valeria Valbuena, and Ana Cheng. They contributed to various parts of this project, especially constructing the protein expression plasmids and growing $C$. elegans.

\section{Authors' Contributions}

MJT, ERC, DSR, and KMW designed and performed the experiments. ERC, $\mathrm{DSR}$, and KMW performed computational analyses. KMW wrote the manuscript with assistance from MJT, ERC, and DSR. KMW supervised the project and assembled the figures.

\section{Funding}

This project was supported by the New College Student Research and Travel Grant program. Some molecular graphics and analyses were performed with UCSF Chimera, developed by the Resource for Biocomputing, Visualization, and Informatics at the University of California, San Francisco, with support from NIH P41-GM103311. The Caenorhabditis Genetics Center (CGC) is supported by the National Institutes of Health - Office of Research Infrastructure Programs (P40 OD010440).

\section{Conflict of Interest}

The authors declare that they have no conflicts of interest with the contents of this article.

\section{References}

1. Goward, C. R., and Nicholls, D. J. (1994) Malate dehydrogenase: a model for structure, evolution, and catalysis. Protein Sci. 3, 1883-1888

2. Minárik, P., Tomásková, N., Kollárová, M., and Antalík, M. (2002) Malate dehydrogenases--structure and function. Gen. Physiol. Biophys. 21, 257-265

3. Musrati, R. A., Kollárová, M., Mernik, N., and Mikulásová, D. (1998) Malate 
dehydrogenase: distribution, function and properties. Gen. Physiol. Biophys. 17, 193-210

4. Agüero, F., Noé, G., Hellman, U., Repetto, Y., Zaha, A., and Cazzulo, J. J. (2004) Purification, cloning, and expression of the mitochondrial malate dehydrogenase (mMDH) from protoscolices of Echinococcus granulosus. Mol. Biochem. Parasitol. 137, 207-214

5. Chetri, P. B., Shukla, R., and Tripathi, T. (2020) Identification and characterization of cytosolic malate dehydrogenase from the liver fluke Fasciola gigantica. Sci. Rep. 10, 13372

6. Nava, G., Laclette, J. P., Bobes, R., Carrero, J. C., Reyes-Vivas, H., Enriquez-Flores, S., Mendoza-Hernández, G., and Plancarte, A. (2011) Cloning, sequencing and functional expression of cytosolic malate dehydrogenase from Taenia solium: Purification and characterization of the recombinant enzyme. Exp. Parasitol. 128, 217-224

7. Plancarte, A., Nava, G., and Mendoza-Hernández, G. (2009) Purification, properties, and kinetic studies of cytoplasmic malate dehydrogenase from Taenia solium cysticerci. Parasitol. Res. 105, 175-183

8. Zheng, N., Xu, J., Wu, Z., Chen, J., Hu, X., Song, L., Yang, G., Ji, C., Chen, S., Gu, S., Ying, K., and Yu, X. (2005) Clonorchis sinensis: molecular cloning and functional expression of novel cytosolic malate dehydrogenase. Exp. Parasitol. 109, 220-227

9. Zheng, N., Huang, B., Xu, J., Huang, S., Chen, J., Hu, X., Ji, C., Ying, K., and $\mathrm{Yu}, \mathrm{X}$. (2008) Cloning and expression of mitochondrial malate dehydrogenase of Clonorchis sinensis. Parasitol. Res. 102, 989-995

10. Fielenbach, N., and Antebi, A. (2008) C. elegans dauer formation and the molecular basis of plasticity. Genes Dev. 22, 2149-2165

11. Ailion, M., and Thomas, J. H. (2000) Dauer formation induced by high temperatures in Caenorhabditis elegans. Genetics. 156, 1047-1067

12. Golden, J. W., and Riddle, D. L. (1984) The Caenorhabditis elegans dauer larva: Developmental effects of pheromone, food, and temperature. Dev. Biol. 102, 368-378

13. Klass, M., and Hirsh, D. (1976) Non-ageing developmental variant of Caenorhabditis elegans. Nature. 260, 523-525

14. Erkut, C., Gade, V. R., Laxman, S., and Kurzchalia, T. V. (2016) The glyoxylate shunt is essential for desiccation tolerance in $C$. elegans and budding yeast. eLife. 5, e13614

15. Kimura, K. D., Tissenbaum, H. A., Liu, Y., and Ruvkun, G. (1997) daf-2, an insulin receptor-like gene that regulates longevity and diapause in Caenorhabditis elegans. Science. 277, 942-946

16. McElwee, J. J., Schuster, E., Blanc, E., Thornton, J., and Gems, D. (2006) Erratum to "Diapause-associated metabolic traits reiterated in long-lived daf-2 mutants in the nematode Caenorhabditis elegans" [Mech. Ageing Dev. 127 (5) (2006) 458-472]. Mech. Ageing Dev. 127, 922-936

17. Penkov, S., Kaptan, D., Erkut, C., Sarov, M., Mende, F., and Kurzchalia, T. V. (2015) Integration of carbohydrate metabolism and redox state controls dauer larva formation in Caenorhabditis elegans. Nat. Commun. 6, 8060 
18. Liu, F., Thatcher, J. D., Barral, J. M., and Epstein, H. F. (1995) Bifunctional glyoxylate cycle protein of Caenorhabditis elegans: a developmentally regulated protein of intestine and muscle. Dev. Biol. 169, 399-414

19. O'Riordan, V. B., and Burnell, A. M. (1990) Intermediary metabolism in the dauer larva of the nematode Caenorhabditis elegans-II. The glyoxylate cycle and fatty-acid oxidation. Comp. Biochem. Physiol. Part B Comp. Biochem. 95, 125-130

20. Vanfleteren, J. R., and De Vreese, A. (1995) The gerontogenes age-1 and daf-2 determine metabolic rate potential in aging Caenorhabditis elegans. FASEB J. 9, 1355-1361

21. Wang, J., and Kim, S. K. (2003) Global analysis of dauer gene expression in Caenorhabditis elegans. Development. 130, 1621-1634

22. Birktoft, J. J., Rhodes, G., and Banaszak, L. J. (1989) Refined crystal structure of cytoplasmic malate dehydrogenase at $2.5-\AA$ resolution. Biochemistry. 28, 6065-6081

23. Gleason, W. B., Fu, Z., Birktoft, J., and Banaszak, L. (1994) Refined crystal structure of mitochondrial malate dehydrogenase from porcine heart and the consensus structure for dicarboxylic acid oxidoreductases. Biochemistry. 33, 2078-2088

24. Hall, M. D., and Banaszak, L. J. (1993) Crystal structure of a ternary complex of Escherichia coli malate dehydrogenase citrate and NAD at 1.9 Å resolution. J. Mol. Biol. 232, 213-222

25. Kelly, C. A., Nishiyama, M., Ohnishi, Y., Beppu, T., and Birktoft, J. J. (1993) Determinants of protein thermostability observed in the 1.9-A crystal structure of malate dehydrogenase from the thermophilic bacterium Thermus flavus. Biochemistry. 32, 3913-3922

26. Roderick, S. L., and Banaszak, L. J. (1986) The three-dimensional structure of porcine heart mitochondrial malate dehydrogenase at 3.0- $\AA$ resolution. J. Biol. Chem. 261, 9461-9464

27. Irimia, A., Vellieux, F. M. D., Madern, D., Zaccaï, G., Karshikoff, A., Tibbelin, G., Ladenstein, R., Lien, T., and Birkeland, N.-K. (2004) The 2.9-A resolution crystal structure of malate dehydrogenase from Archaeoglobus fulgidus: Mechanisms of oligomerisation and thermal stabilisation. J. Mol. Biol. 335, 343-356

28. Lee, B. I., Chang, C., Cho, S. J., Eom, S. H., Kim, K. K., Yu, Y. G., and Suh, S. W. (2001) Crystal structure of the MJ0490 gene product of the hyperthermophilic archaebacterium Methanococcus jannaschii, a novel member of the lactate/malate family of dehydrogenases. J. Mol. Biol. 307, 1351-1362

29. Lee, D., Hong, J., and Kim, K.-J. (2019) Crystal structure and biochemical characterization of malate dehydrogenase from Metallosphaera sedula. Biochem. Biophys. Res. Commun. 509, 833-838

30. Richard, S. B., Madern, D., Garcin, E., and Zaccai, G. (2000) Halophilic Adaptation: Novel Solvent Protein Interactions Observed in the 2.9 and 2.6 A Resolution Structures of the Wild Type and a Mutant of Malate Dehydrogenase from Haloarcula marismortui. Biochemistry. 39, 992-1000 
31. Yennaco, L. J., Hu, Y., and Holden, J. F. (2007) Characterization of malate dehydrogenase from the hyperthermophilic archaeon Pyrobaculum islandicum. Extremophiles. 11, 741-746

32. Madeira, F., Park, Y. mi, Lee, J., Buso, N., Gur, T., Madhusoodanan, N., Basutkar, P., Tivey, A. R. N., Potter, S. C., Finn, R. D., and Lopez, R. (2019) The EMBL-EBI search and sequence analysis tools APIs in 2019. Nucleic Acids Res. 47, W636-W641

33. Claros, M. G., and Vincens, P. (1996) Computational Method to Predict Mitochondrially Imported Proteins and their Targeting Sequences. Eur. J. Biochem. 241, 779-786

34. Fukasawa, Y., Tsuji, J., Fu, S.-C., Tomii, K., Horton, P., and Imai, K. (2015) MitoFates: improved prediction of mitochondrial targeting sequences and their cleavage sites. Mol. Cell. Proteomics. 14, 1113-1126

35. Laemmli, U. K. (1970) Cleavage of structural proteins during the assembly of the head of bacteriophage T4. Nature. 277, 680

36. Lawrence, A.-M., and Besir, H. (2009) Staining of Proteins in Gels with Coomassie G-250 without Organic Solvent and Acetic Acid. J. Vis. Exp. $10.3791 / 1350$

37. Mains, P. E., and McGhee, J. D. (1999) Biochemistry of C. elegans. in C. elegans: A practical approach (Hope, I. A. ed), pp. 227-244, Practical Approach, Oxford University Press, Oxford, UK

38. Morrissey, J. H. (1981) Silver stain for proteins in polyacrylamide gels: a modified procedure with enhanced uniform sensitivity. Anal. Biochem. 117, 307-310

39. Waterhouse, A., Bertoni, M., Bienert, S., Studer, G., Tauriello, G., Gumienny, R., Heer, F. T., de Beer, T. A. P., Rempfer, C., Bordoli, L., Lepore, R., and Schwede, T. (2018) SWISS-MODEL: homology modelling of protein structures and complexes. Nucleic Acids Res. 46, W296-W303

40. Studer, G., Tauriello, G., Bienert, S., Biasini, M., Johner, N., and Schwede, T. (2021) ProMod3-A versatile homology modelling toolbox. PLoS Comput. Biol. 17, e1008667

41. Studer, G., Rempfer, C., Waterhouse, A. M., Gumienny, R., Haas, J., and Schwede, T. (2020) QMEANDisCo-distance constraints applied on model quality estimation. Bioinformatics. 36, 1765-1771

42. Krieger, E., Joo, K., Lee, J., Lee, J., Raman, S., Thompson, J., Tyka, M., Baker, D., and Karplus, K. (2009) Improving physical realism, stereochemistry, and side-chain accuracy in homology modeling: Four approaches that performed well in CASP8. Proteins. 77 Suppl 9, 114-122

43. Sippl, M. J. (1993) Recognition of errors in three-dimensional structures of proteins. Proteins Struct. Funct. Bioinforma. 17, 355-362

44. Wiederstein, M., and Sippl, M. J. (2007) ProSA-web: interactive web service for the recognition of errors in three-dimensional structures of proteins. Nucleic Acids Res. 35, W407-W410

45. Lovell, S. C., Davis, I. W., Arendall, W. B., de Bakker, P. I. W., Word, J. M., Prisant, M. G., Richardson, J. S., and Richardson, D. C. (2003) Structure validation by $C \alpha$ geometry: $\Phi, \psi$ and $C \beta$ deviation. Proteins. 50, 437-450 
46. Williams, C. J., Headd, J. J., Moriarty, N. W., Prisant, M. G., Videau, L. L., Deis, L. N., Verma, V., Keedy, D. A., Hintze, B. J., Chen, V. B., Jain, S., Lewis, S. M., Arendall, W. B., Snoeyink, J., Adams, P. D., Lovell, S. C., Richardson, J. S., and Richardson, D. C. (2018) MolProbity: More and better reference data for improved all-atom structure validation. Protein Sci. 27, 293-315

47. Bowie, J. U., Lüthy, R., and Eisenberg, D. (1991) A method to identify protein sequences that fold into a known three-dimensional structure. Science. 253, 164-170

48. Eisenberg, D., Lüthy, R., and Bowie, J. U. (1997) VERIFY3D: Assessment of protein models with three-dimensional profiles. in Methods in Enzymology, pp. 396-404, Macromolecular Crystallography Part B, Academic Press, 277, 396-404

49. Lüthy, R., Bowie, J. U., and Eisenberg, D. (1992) Assessment of protein models with three-dimensional profiles. Nature. 356, 83-85

50. Pettersen, E. F., Goddard, T. D., Huang, C. C., Couch, G. S., Greenblatt, D. M., Meng, E. C., and Ferrin, T. E. (2004) UCSF Chimera--a visualization system for exploratory research and analysis. J. Comput. Chem. 25, 1605-1612

51. Chapman, A. D., Cortés, A., Dafforn, T. R., Clarke, A. R., and Brady, R. L. (1999) Structural basis of substrate specificity in malate dehydrogenases: crystal structure of a ternary complex of porcine cytoplasmic malate dehydrogenase, alpha-ketomalonate and tetrahydoNAD. J. Mol. Biol. 285, 703-712

52. Holt, S. J., and Riddle, D. L. (2003) SAGE surveys C. elegans carbohydrate metabolism: evidence for an anaerobic shift in the long-lived dauer larva. Mech. Ageing Dev. 124, 779-800

53. Bell, J. K., Yennawar, H. P., Wright, S. K., Thompson, J. R., Viola, R. E., and Banaszak, L. J. (2001) Structural analyses of a malate dehydrogenase with a variable active site. J. Biol. Chem. 276, 31156-31162

54. Fukushima, T., Decker, R. V., Anderson, W. M., and Spivey, H. O. (1989) Substrate Channeling of NADH and Binding of Dehydrogenases to Complex I. J. Biol. Chem. 264, 16483-16488

55. Halper, L. A., and Srere, P. A. (1977) Interaction between citrate synthase and mitochondrial malate dehydrogenase in the presence of polyethylene glycol. Arch. Biochem. Biophys. 184, 529-534

56. Meyer, F. M., Gerwig, J., Hammer, E., Herzberg, C., Commichau, F. M., Völker, U., and Stülke, J. (2011) Physical interactions between tricarboxylic acid cycle enzymes in Bacillus subtilis: Evidence for a metabolon. Metab. Eng. 13, 18-27

57. Morgunov, I., and Srere, P. A. (1998) Interaction between citrate synthase and malate dehydrogenase. Substrate channeling of oxaloacetate. J. Biol. Chem. 273, 29540-29544

58. Wu, F., and Minteer, S. (2015) Krebs Cycle Metabolon: Structural Evidence of Substrate Channeling Revealed by Cross-Linking and Mass Spectrometry. Angew. Chem. Int. Ed. 54, 1851-1854 
59. Michaelis, L., and Menten, M. L. (1913) Die Kinetik der Invertinwirkung. Biochem Z. 49, 333-369

60. Michaelis, L., Menten, M. L., Johnson, K. A., and Goody, R. S. (2011) The original Michaelis constant: translation of the 1913 Michaelis-Menten paper. Biochemistry. 50, 8264-8269

61. Srere, P. A., Mattiasson, B., and Mosbach, K. (1973) An Immobilized Three-Enzyme System: A Model for Microenvironmental Compartmentation in Mitochondria. Proc. Natl. Acad. Sci. U. S. A. 70, 2534-2538

62. Dasika, S. K., Vinnakota, K. C., and Beard, D. A. (2015) Characterization of the Kinetics of Cardiac Cytosolic Malate Dehydrogenase and Comparative Analysis of Cytosolic and Mitochondrial Isoforms. Biophys. J. 108, 420-430

63. McMullen, P. D., Aprison, E. Z., Winter, P. B., Amaral, L. A. N., Morimoto, R. I., and Ruvinsky, I. (2012) Macro-level Modeling of the Response of $C$. elegans Reproduction to Chronic Heat Stress. PLOS Comput. Biol. 8, e1002338

64. Plagens, R. N., Mossiah, I., Kim Guisbert, K. S., and Guisbert, E. (2021) Chronic temperature stress inhibits reproduction and disrupts endocytosis via chaperone titration in Caenorhabditis elegans. BMC Biol. 19, 75

65. Goldenzweig, A., and Fleishman, S. J. (2018) Principles of Protein Stability and Their Application in Computational Design. Annu. Rev. Biochem. 87, 105-129

66. Brininger, C., Spradlin, S., Cobani, L., and Evilia, C. (2018) The more adaptive to change, the more likely you are to survive: Protein adaptation in extremophiles. Semin. Cell Dev. Biol. 84, 158-169

67. Chakravorty, D., Khan, M. F., and Patra, S. (2017) Multifactorial level of extremostability of proteins: can they be exploited for protein engineering? Extrem. Life Extreme Cond. 21, 419-444

68. Jaenicke, R., and Böhm, G. (1998) The stability of proteins in extreme environments. Curr. Opin. Struct. Biol. 8, 738-748

69. Dalhus, B., Saarinen, M., Sauer, U. H., Eklund, P., Johansson, K., Karlsson, A., Ramaswamy, S., Bjørk, A., Synstad, B., Naterstad, K., Sirevåg, R., and Eklund, H. (2002) Structural Basis for Thermophilic Protein Stability: Structures of Thermophilic and Mesophilic Malate Dehydrogenases. J. Mol. Biol. 318, 707-721

70. Li, C., Heatwole, J., Soelaiman, S., and Shoham, M. (1999) Crystal structure of a thermophilic alcohol dehydrogenase substrate complex suggests determinants of substrate specificity and thermostability. Proteins. 37, 619-627

71. Matthews, B. W., Nicholson, H., and Becktel, W. J. (1987) Enhanced protein thermostability from site-directed mutations that decrease the entropy of unfolding. Proc. Natl. Acad. Sci. U. S. A. 84, 6663-6667

72. Yip, K. S., Britton, K. L., Stillman, T. J., Lebbink, J., de Vos, W. M., Robb, F. T., Vetriani, C., Maeder, D., and Rice, D. W. (1998) Insights into the molecular basis of thermal stability from the analysis of ion-pair networks in the glutamate dehydrogenase family. Eur. J. Biochem. 255, 336-346

73. Trejo, F., Gelpí, J. LI., Ferrer, A., Boronat, A., Busquets, M., and Cortés, A. 
(2001) Contribution of engineered electrostatic interactions to the stability of cytosolic malate dehydrogenase. Protein Eng. Des. Sel. 14, 911-917

74. Müller, J., and Klein, C. (1982) Stability of dehydrogenases. III. Malate dehydrogenases. Biochim. Biophys. Acta. 707, 133-141

75. lijima, S., Saiki, T., and Beppu, T. (1980) Physicochemical and catalytic properties of thermostable malate dehydrogenase from an extreme thermophile Thermus flavus AT-62. Biochim. Biophys. Acta. 613, 1-9

76. Nishiyama, M., Matsubara, N., Yamamoto, K., lijima, S., Uozumi, T., and Beppu, T. (1986) Nucleotide sequence of the malate dehydrogenase gene of Thermus flavus and its mutation directing an increase in enzyme activity. J. Biol. Chem. 261, 14178-14183

77. Duffield, M. L., Nicholls, D. J., Atkinson, T., and Scawen, M. D. (1994) An investigation of the thermal stabilities of two malate dehydrogenases by comparison of their three-dimensional structures. J. Mol. Graph. 12, 14-21

78. Fernie, A. R., Zhang, Y., and Sweetlove, L. J. (2018) Passing the Baton: Substrate Channelling in Respiratory Metabolism. Res. Wash. DC. 2018, 1539325

79. Schmitt, D. L., and An, S. (2017) Spatial Organization of Metabolic Enzyme Complexes in Cells. Biochemistry. 56, 3184-3196

80. Tompa, P., Batke, J., Ovadi, J., Welch, G. R., and Srere, P. A. (1987) Quantitation of the interaction between citrate synthase and malate dehydrogenase. J. Biol. Chem. 262, 6089-6092

81. Golding, G. B., and Dean, A. M. (1998) The structural basis of molecular adaptation. Mol. Biol. Evol. 15, 355-369

82. Madern, D. (2002) Molecular evolution within the L-malate and L-lactate dehydrogenase super-family. J. Mol. Evol. 54, 825-840

83. Baum, D. A., and Baum, B. (2014) An inside-out origin for the eukaryotic cell. BMC Biol. 12, 76

84. Sagan, L. (1967) On the origin of mitosing cells. J. Theor. Biol. 14, 225-274

85. Imachi, H., Nobu, M. K., Nakahara, N., Morono, Y., Ogawara, M., Takaki, Y., Takano, Y., Uematsu, K., Ikuta, T., Ito, M., Matsui, Y., Miyazaki, M., Murata, K., Saito, Y., Sakai, S., Song, C., Tasumi, E., Yamanaka, Y., Yamaguchi, T., Kamagata, Y., Tamaki, H., and Takai, K. (2020) Isolation of an archaeon at the prokaryote-eukaryote interface. Nature. 577, 519-525

86. Spang, A., Saw, J. H., Jørgensen, S. L., Zaremba-Niedzwiedzka, K., Martijn, J., Lind, A. E., van Eijk, R., Schleper, C., Guy, L., and Ettema, T. J. G. (2015) Complex archaea that bridge the gap between prokaryotes and eukaryotes. Nature. 521, 173-179

87. Ge, Y.-D., Cao, Z.-Y., Wang, Z.-D., Chen, L.-L., Zhu, Y.-M., and Zhu, G.-P. (2010) Identification and biochemical characterization of a thermostable malate dehydrogenase from the mesophile Streptomyces coelicolor A3(2). Biosci. Biotechnol. Biochem. 74, 2194-2201

88. Wang, Z.-D., Wang, B.-J., Ge, Y.-D., Pan, W., Wang, J., Xu, L., Liu, A.-M., and Zhu, G.-P. (2011) Expression and identification of a thermostable malate dehydrogenase from multicellular prokaryote Streptomyces avermitilis MA-4680. Mol. Biol. Rep. 38, 1629-1636 
89. Swanson, M. M., and Riddle, D. L. (1981) Critical periods in the development of the Caenorhabditis elegans dauer larva. Dev. Biol. 84, 27-40

90. Kenyon, C., Chang, J., Gensch, E., Rudner, A., and Tabtiang, R. (1993) A C. elegans mutant that lives twice as long as wild type. Nature. 366, 461-464

91. Fuchs, S., Bundy, J. G., Davies, S. K., Viney, J. M., Swire, J. S., and Leroi, A. M. (2010) A metabolic signature of long life in Caenorhabditis elegans. BMC Biol. 8, 14

92. Sinha, A., Sommer, R. J., and Dieterich, C. (2012) Divergent gene expression in the conserved dauer stage of the nematodes Pristionchus pacificus and Caenorhabditis elegans. BMC Genomics. 13, 254

93. Ruzanov, P., Riddle, D. L., Marra, M. A., McKay, S. J., and Jones, S. M. (2007) Genes that may modulate longevity in $C$. elegans in both dauer larvae and long-lived daf-2 adults. Exp. Gerontol. 42, 825-839

94. Depuydt, G., Xie, F., Petyuk, V. A., Smolders, A., Brewer, H. M., Camp, D. G., Smith, R. D., and Braeckman, B. P. (2014) LC-MS Proteomics Analysis of the Insulin/IGF-1-Deficient Caenorhabditis elegans daf-2(e1370) Mutant Reveals Extensive Restructuring of Intermediary Metabolism. J. Proteome Res. 13, 1938-1956

95. Dong, M.-Q., Venable, J. D., Au, N., Xu, T., Park, S. K., Cociorva, D., Johnson, J. R., Dillin, A., and Yates, J. R. (2007) Quantitative Mass Spectrometry Identifies Insulin Signaling Targets in C. elegans. Science. 317, 660-663

96. Penkov, S., Raghuraman, B. K., Erkut, C., Oertel, J., Galli, R., Ackerman, E. J. M., Vorkel, D., Verbavatz, J.-M., Koch, E., Fahmy, K., Shevchenko, A., and Kurzchalia, T. V. (2020) A metabolic switch regulates the transition between growth and diapause in C. elegans. BMC Biol. 18, 31

97. O'Riordan, V. B., and Burnell, A. M. (1989) Intermediary metabolism in the dauer larva of the nematode Caenorhabditis elegans-1. Glycolysis, gluconeogenesis, oxidative phosphorylation and the tricarboxylic acid cycle. Comp. Biochem. Physiol. Part B Comp. Biochem. 92, 233-238

98. Föll, R. L., Pleyers, A., Lewandovski, G. J., Wermter, C., Hegemann, V., and Paul, R. J. (1999) Anaerobiosis in the nematode Caenorhabditis elegans. Comp. Biochem. Physiol. B Biochem. Mol. Biol. 124, 269-280

99. Takamiya, S., Matsui, T., Taka, H., Murayama, K., Matsuda, M., and Aoki, T. (1999) Free-Living Nematodes Caenorhabditis elegans Possess in Their Mitochondria an Additional Rhodoquinone, an Essential Component of the Eukaryotic Fumarate Reductase System. Arch. Biochem. Biophys. 371, 284-289

100. Butler, J. A., Mishur, R. J., Bokov, A. F., Hakala, K. W., Weintraub, S. T., and Rea, S. L. (2012) Profiling the anaerobic response of C. elegans using GC-MS. PloS One. 7, e46140

101. Butler, J. A., Ventura, N., Johnson, T. E., and Rea, S. L. (2010) Long-lived mitochondrial (Mit) mutants of Caenorhabditis elegans utilize a novel metabolism. FASEB J. Off. Publ. Fed. Am. Soc. Exp. Biol. 24, 4977-4988 
102. Edwards, C. B., Copes, N., Brito, A. G., Canfield, J., and Bradshaw, P. C. (2013) Malate and fumarate extend lifespan in Caenorhabditis elegans. PloS One. 8, e58345

103. Rea, S., and Johnson, T. E. (2003) A metabolic model for life span determination in Caenorhabditis elegans. Dev. Cell. 5, 197-203

104. Williams, D. S., Cash, A., Hamadani, L., and Diemer, T. (2009) Oxaloacetate supplementation increases lifespan in Caenorhabditis elegans through an AMPK/FOXO-dependent pathway. Aging Cell. 8, 765-768

105. Honda, Y., Tanaka, M., and Honda, S. (2010) Trehalose extends longevity in the nematode Caenorhabditis elegans. Aging Cell. 9, 558-569

106. Rasulova, M., Zečić, A., Monje Moreno, J. M., Vandemeulebroucke, L., Dhondt, I., and Braeckman, B. P. (2021) Elevated Trehalose Levels in C. elegans daf-2 Mutants Increase Stress Resistance, Not Lifespan. Metabolites. 10.3390/metabo11020105

107. Hottiger, T., Virgilio, C. D., Hall, M. N., Boller, T., and Wiemken, A. (1994) The role of trehalose synthesis for the acquisition of thermotolerance in yeast II. Physiological concentrations of trehalose increase the thermal stability of proteins in vitro. Eur. J. Biochem. 219, 187-193

108. Singer, M. A., and Lindquist, S. (1998) Multiple Effects of Trehalose on Protein Folding In Vitro and In Vivo. Mol. Cell. 1, 639-648

109. Depuydt, G., Shanmugam, N., Rasulova, M., Dhondt, I., and Braeckman, B. P. (2016) Increased Protein Stability and Decreased Protein Turnover in the Caenorhabditis elegans Ins/IGF-1 daf-2 Mutant. J. Gerontol. Ser. Biol Sci Med Sci. 71, 1553-1559

110. Gallo, M., Park, D., Luciani, D. S., Kida, K., Palmieri, F., Blacque, O. E., Johnson, J. D., and Riddle, D. L. (2011) MISC-1/OGC Links Mitochondrial Metabolism, Apoptosis and Insulin Secretion. PLOS ONE. 6, e17827

111. Palmieri, L., Pardo, B., Lasorsa, F. M., del Arco, A., Kobayashi, K., lijima, M., Runswick, M. J., Walker, J. E., Saheki, T., Satrústegui, J., and Palmieri, F. (2001) Citrin and aralar1 are $\mathrm{Ca}^{2+}$-stimulated aspartate/glutamate transporters in mitochondria. EMBO J. 20, 5060-5069

112. Shaye, D. D., and Greenwald, I. (2011) OrthoList: A Compendium of C. elegans Genes with Human Orthologs. PLOS ONE. 6, e20085

113. Bernstein, L. H., Grisham, M. B., Cole, K. D., and Everse, J. (1978) Substrate inhibition of the mitochondrial and cytoplasmic malate dehydrogenases. J. Biol. Chem. 253, 8697-8701

114. Stein, L. R., and Imai, S. (2012) The dynamic regulation of NAD metabolism in mitochondria. Trends Endocrinol. Metab. 23, 420-428

115. Waterhouse, A. M., Procter, J. B., Martin, D. M. A., Clamp, M., and Barton, G. J. (2009) Jalview Version 2-a multiple sequence alignment editor and analysis workbench. Bioinformatics. 25, 1189-1191 


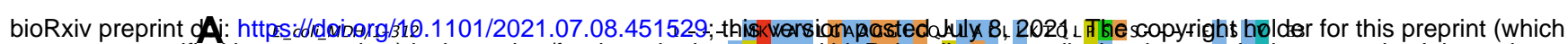

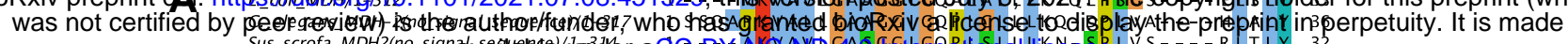

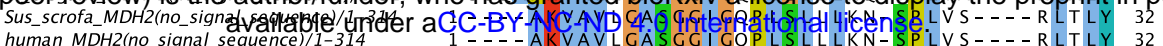
1 KAPV

Figure 1.

MDH

sequence alignments

and analysis T._thermophilus_MDH/1-326 C._elegans_MDH-1/1-335 Sus_scrofa_MDH1/1-333
human $M D H 1 / 1-333$

Consensus

E. coli_MDH/1-312

C._elegans $M D H-2$ (no signal_sequence) $/ 1-317$ Sus_scrofa_MDH2(no_signal_sequence)/1-314 human_MDH2(no_signal_sequence)/1-314 T._thermophilus_MDH/1-326 C._elegans_MDH-1/1-335 Sus_scrofa_MDH1/1-333 human_MDH1/1-333

Consensus

E. coli_MDH/1-312

C._elegans_MDH-2(no_signal_sequence) $/ 1-317$ Sus_scrofa_MDH2(no_signal_sequence) $/ 1-314$ human_MDH2(no_signal_sequence)/1-314 T._thermophilus_MDH/1-326

C._elegans_MDH-1/1-335

Sus_scrofa_MDH1/1-333

human_MDH1/1-333

Consensus 1 - KAP VRVAVTGAAGQ I GY SLLFR I AAGEMLGKDQP V I LQLL 40
1 - SAPLRVLVTGAAGQ I GYS I V IR IADGTVFGKEQPVELVLL 40 1 - SEP I RVLVTGAAGQ I AY SLLYS I GNGSVFCKDQP I I LVLL 40 1 - SEP I RVLVTGAAGQIAYSLLYSIGNGSVFGKDQP I I LVLL 40

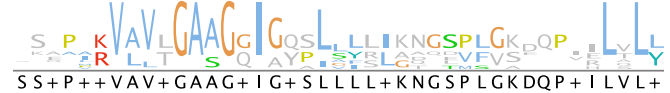

34 D I APV - - - TPGVAVDLSHIPTAVK IKGFSGEDAT - PALEGA 70 37 DVV-N - - TPGVAADLSHIDSNAKVTAHTGPKELYAAVENA 73 33 D I A-H- - TPGVAADLSHIETRATVKGYLGPEQLPDCLKGC 69 33 D I A-H- - TPGVAADISH IETKAAVKGYLGPEQLPDCLKGC 69 41 E I PQAMKALEGVVMELEDCAF-PLLAGLEATDDPKVAFKDA 80 41 E I PQAMKALEGVVMELEDCAF-P L LAGLEATDDPKVAFKDA
41 DVPQCSN I LEGVVFELQDCAL-PTLFSVVAVTDEKSAFTG I 80 41 D I TPMMGV LDGVLMELQDCAL - P LLKDV I ATDKEE I AFKDL 80 41 D I TPMMGV LDGVLMELQDCAL - P LLKDV IATDKEDVAFKDL 80

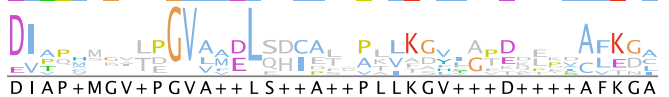
71 DVVL I SAGVARKPGMDR SDLFNVNAG I VKNLVQQVAKTCP - 110
74 DV I VI PAGVPRKPGMTRDDLFNTNAG I VRDLAAV IAKASP- 113 74 DV I V I PAGVPRKPGMTR DDLFNTNAG I VRDLAAV I AKASP- 113
70 DVVV I PAGVPRKP GMTRDDLFNTNAT I VATLTAACAQHCP- 109 70 DVVV I PAGVPRKPGMTRDDLFNTNAT I VAT LTAACAQHCP- 109
70 DVVV I PAGVPRKPGMTRDDLFNTNAT I VATLTAACAQHCP- 109 70 DVVVI PAGVPRKP GMTR DDLFNTNAT I VATLTAACAQHCP- 109 81 DYALLVGAAPRKAGMERR DLLQVNGK I FTEQGRALAEVAKK 121
81 DYAFLVGAMPRREGMERKDLLAANVK I FKSQGKALAEYAKP 121 81 DVA I LVGSMPRRDGMERKDLLKANVK I FKCQGAALDKYAKK 121 81 DVA I LVGSMPRREGMERKDLLKANVK I FK SQGAALDKYAKK 121

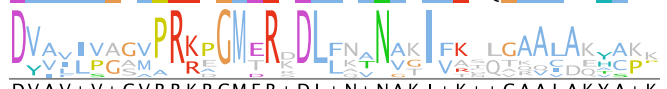

E. coli $M D H / 1-312$

111 KACI G I ITNPVNTTVA I AAEVLKKAGVYDKNKLFGVTTLD I 151

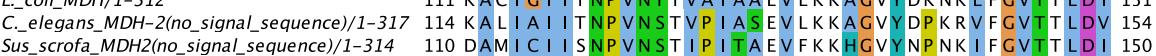

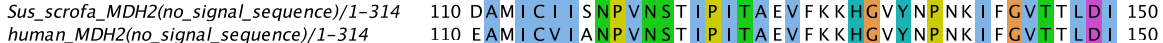
$\begin{array}{ll}\text { human_MDH2(no_signal_sequence)/1-314 } & 110 \text { EAM I CV I ANP VNST I P I TAEVFKKHGVYNPNK I FGVTTLD I } 150 \\ \text { T_thermophilus_MDH/1-326 } & 122 \text { DVKVLVVGNPANTNAL I AYK - - NAPGLNPRNFTAMTRLDH } 159\end{array}$ $\begin{array}{ll}\text { T._thermophilus_MDH/1-326 } & 122 \text { DVKVLVVGNPANTNAL I AYK-- NAPGLNPRNFTAMTR LDH } 159 \\ \text { C._elegans_MDH-1/1-335 } & 122 \text { T TKV I VVGNPANTNAFI AAKY- - AAGK I PAKNF SAMTR LDH } 160\end{array}$ $\begin{array}{ll}\text { C._elegans_MDH-1/1-335 } & 122 \text { TTKV I VVGNPANTNAF I AAKY - AAGK I PAKNFSAMTR L DH } 160 \\ \text { Sus_scrofa_MDH1/1-333 } & 122 \text { SVKV I VVGNPANTNCLTASK- - SAPS I PKENFSCLTRLDH } 159\end{array}$

122 SVKV I VVGNPANTNCLTASK- - - SAP SIPKENFSCLTRLDH 159

Consensus

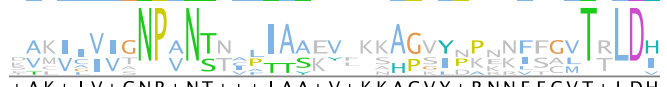

$+A K+I V+C N P+N T+++I A A+V+K K A G V Y+P N N F F C V T+L D H$

E._coli_MDH/1-312

152 I R SNTFVAELKGKQPGEVEVPVI GGHSGVT I LPLLSQV-PG 191 C._elegans_MDH-2(no signal sequence)/1-317 155 VR SQAFVSELKGHDASKTVVPVVGGHACITI I P LLSQVKPS 195

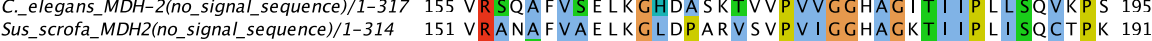

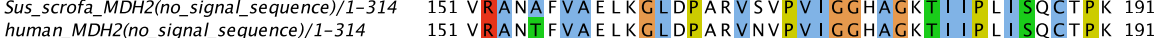
$\begin{array}{ll}\text { human_MDH2(no_signal_sequence)/1-314 } & 151 \text { VRANTFVAELKGLDPAR VNVPVI GGHAGK TI I L I SCTPK } 191 \\ \text { T. thermophilus_MDH/1-326 } & 160 \text { NRAKAQLAKKTGTGVDR I RRMTVWGNHSSTMFPDLFHAEVD } 200\end{array}$ C. elegans $\mathrm{MDH}-1 / 1-335$ Sus_scrofa_MDH1/1-333 human_MDH1/1-333

161 NRALAQLALKTGTT I GNVKNV I I WGNHSGTQFPDVTHATVN 201 160 NRAKAQ I ALK LGVTSDDVKNV I I WGNHS STQYP DVNHAKVK 200 160 NRAKAQ I ALKLGVTANDVKNV I I WGNHS STQYPDVNHAKVK 200

Consensus

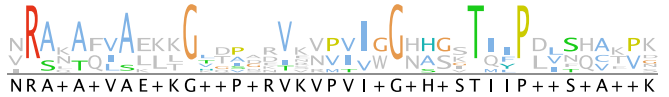

E. coli_MDH/1-312

192 VSFTEQEV- - - - - - - - - ADLTKR I QNAGT EVVEAKAGGG 221 C. elegans.MDH-2(no signal_sequence)/1-317 196 TKFSEEE I- - . - . - . SKLTPR I QDAGTEVVNAKAGAC 225

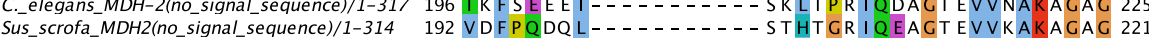

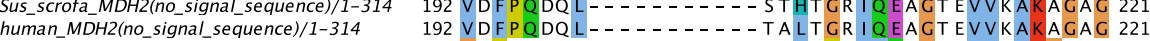
T. thermophilus_Mignal_sequence)/1-314 T._thermophilus_MDH/1-326 Cus_scrofa_MDH- $M / 1 / 1-335$ human $M D H 1 / 1-333$ 201 GRPA- - - LELVDMEWY EKVF I PTVAQRGAA I I QARGA- - 234
202 KNGTETDAYAAVGDNAFLQGPF I ATVQKRGGV I I EKRKL-- 240 201 LQAKEVGVYEAVKDDSWLKGEF I TTVQQRGAAV I KARKL - - 239 201 LQGKEVGVYEALKDDSWLKGEFVTTVQQRGAAV IKARKL - - 239

Consensus

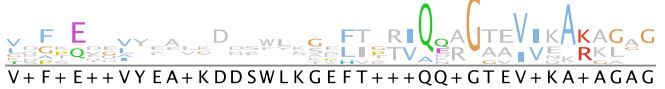

$\bar{V}+F+E++V Y E A+K D D S W L K G E F T+++Q Q+C T E V+K A+A G A G$

E. coli $M D H / 1-312$

222 SATLSMGQAAAR FGLSLVRALQGEQGVVECAYVEGDG- - - 258 C._elegans_MDH-2(no_signal_sequence)/1-317 226 SAT L SMALAGAR FANALVRG I KGEKNV-QCAYVASDA- - - 261 Sus_scrofa_MDH2(no_signal_sequence)/1-314 222 SAT L SMA Y A GAR F V F S L V DAMNG K E G V V E C S F V K S-Q Q- - - - 257 human_MDH2(no_signal_sequence)/1-314 222 SAT L SMAY A GAR F V F S LVDAMNGK E GVVECSFVK S-Q Q - - - 257 T._thermophilus $M D H / 1-326$ C. elegans $M D H-1 / 1-335$ Sus_scrofa $M D H 1 / 1-333$ human_MDH1/1-333

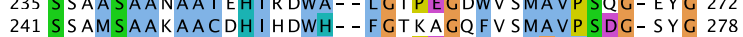
240 S SAM SAAKA I CDHVRDIW- - FGTP EGEFV SMG I I S DGNSYG 278 240 S S AM SAAKA I CDHVRD I W- - FGTPEGEFV SMGV I S DGN SYG 278

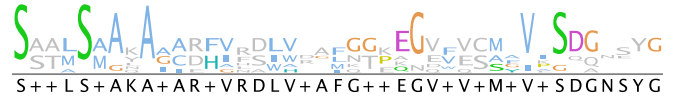

E._coli_MDH/1-312

$S++L S+A K A+A R+V R D L V+A F G++E G V+V+M+V+S D G N S Y G$ C._elegans_MDH-2(no_signal_sequence)/1-317 262 VK CVEY F STPVELGPNGVEKIL L VGKVSAYEQKL I DASVPE 302 Sus_scrofa_MDH2(no_signal_sequence)/1-314 258 ET DCPY F STP LLLGKKG I EKNLC I CK I SPFEEKM I AEA IPE 298 human_MDH2(no_signal_sequence)/1-314 258 ETECTYF STPLLLCKKC I EKN L I GKVS S FE E KM I S DA I PE 298 thermophilus $M D H / 1-326$ C._elegans $\mathrm{MDH}-1 / 1-335$ Sus_scrofa $M D H 1 / 1-333$ human_MDH1/1-333 279 IPQGLI FSFPVT I ECGEWK IVQG- LSFDDFAKGK IAATTKE 318 279 VPDDLLYS FPVT I KDKTWK I VEG- LP INDFSREKMDLTAKE 318 279 VPDDLLYSFPVVI KNKTWK FVEG- LP INDFSREKMDLTAKE 318

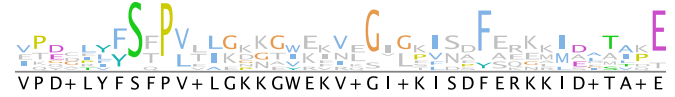

E._coli_MDH/1-312

299 LKK D I A LGEEFVNK - -

C._elegans_MDH-2(no_signal_sequence)/1-317 303 L N K N I A K GV A F V K GN -

Sus_scrofa_MDH2(no_signal_sequence)/1-314 299 LK A S I K K G E E F VK NMK -

human_MDH2(no_signal_sequence)/1-314 299 LK A S I K K GEDF V K T LK -

T._thermophilus_MDH/1-326

C._elegans_MDH-1/1-335

Sus_scrofa_MDH1/1-333

13 LLDEMEQVKALGL L-

319 LEEERDDA LKACDDAN I

human_MDH1/1-333

319 LTEEKESAFEF LS SA- - 
Figure 1. MDH sequence alignments and analysis

\section{B}

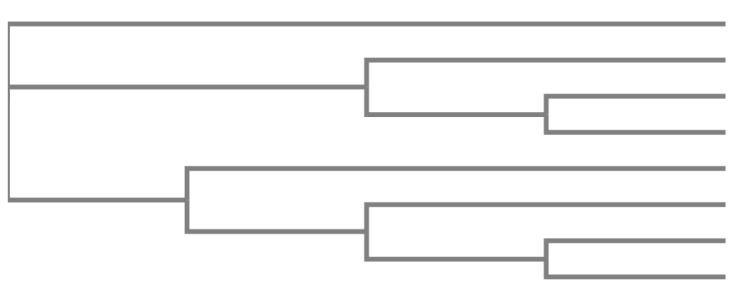

E._coli_MDH 0.20657

C._elegans_MDH-2_no_signal_sequence_ 0.20731

Sus_scrofa_MDH2_no_signal_sequence_0.02796

human_MDH2_no_signal_sequence_0.03255

T._thermophilus_MDH 0.22858

C._elegans_MDH-1 0.20299

Sus_scrofa_MDH1 0.02356

human_MDH1 0.02135

C

\begin{tabular}{|l|l|l|l|l|}
\hline $\begin{array}{l}\text { Sequence } \\
\text { Identities }\end{array}$ & MDH-1 & $\begin{array}{l}\text { T. } \\
\text { thermophilus }\end{array}$ & $\begin{array}{l}\text { S. scrofa } \\
\text { MDH1 }\end{array}$ & human MDH1 \\
\hline MDH-1 & 100 & 54 & 60 & 60 \\
\hline T. thermophilus & & 100 & 55 & 54 \\
\hline S. scrofa MDH1 & & & 100 & 96 \\
\hline human MDH1 & & & & 100 \\
\hline
\end{tabular}

\begin{tabular}{|l|l|l|l|l|}
\hline $\begin{array}{l}\text { Sequence } \\
\text { Identities }\end{array}$ & MDH-2 & E. coli & S. scrofa MDH2 & human MDH2 \\
\hline MDH-2 & 100 & 58 & 60 & 60 \\
\hline E. coli & & 100 & 59 & 59 \\
\hline S. scrofa MDH2 & & & 100 & 94 \\
\hline human MDH2 & & & & 100 \\
\hline
\end{tabular}

Figure 1. MDH sequence alignments and analysis

A. The protein sequences for $C$. elegans $\mathrm{MDH}-1$ (F46E10.10) and MDH-2 (F20H11.3) were aligned with the S. scrofa MDH1 (NP_999039.1) and MDH2 (NP_001231082.1), human MDH1 (NP_005908.1) and MDH2 (P40926.3), T. thermophilus MDH (P10584.1), and E. coli MDH (QIF74064.1) using Clustal Omega (32) and visualized using Jalview (115). Amino acid coloring is based on sequence identity. The MDH1 amino acid numbering starts with the first amino 
acid after the methionine (which is not shown in the sequences), and the MDH2 numbering starts with the first amino acid after cleavage of the mitochondrial import signal sequence. B. The phylogenetic tree for these proteins is a neighbor-joining tree without distance corrections made with Clustal Omega. C. The amino acid sequence identities were calculated by Clustal Omega. 


\section{Figure 2. Recombinant MDH-2 purification}

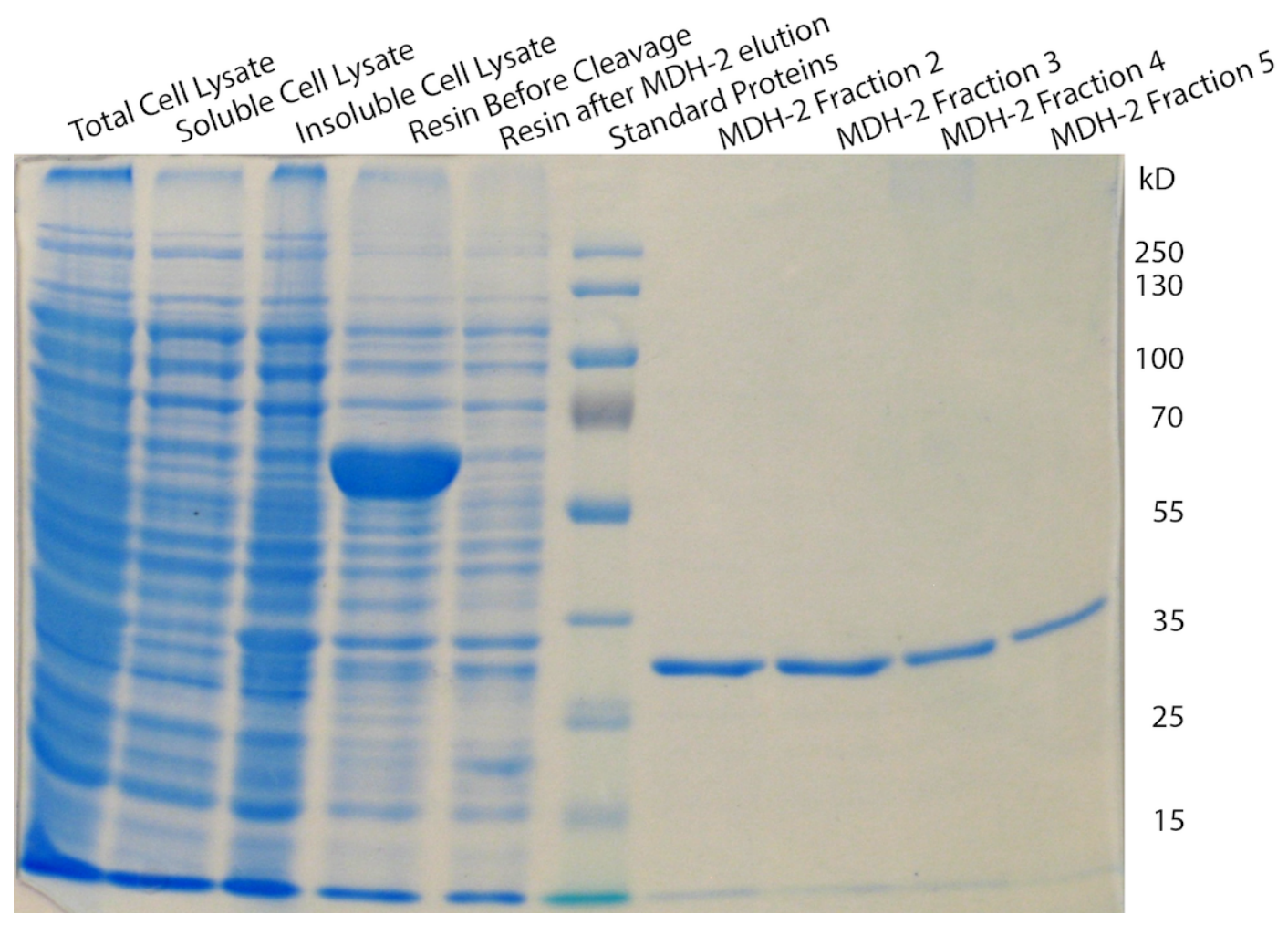

\section{Figure 2. Recombinant MDH-2 purification}

Samples from the purification of recombinant MDH-2 are shown in a $10 \%$ SDS-PAGE gel. The soluble cell lysate containing the MDH-2-CBD fusion protein $(61.2 \mathrm{kDa})$ was run through a chitin resin column, and the protein bound to the resin (lane 4). Then DTT was added to the resin for $24 \mathrm{hr}$. at $4{ }^{\circ} \mathrm{C}$ to induce cleavage of the intein to release $\mathrm{MDH}-2(33.3 \mathrm{kDa})$. The $\mathrm{MDH}-2$ fractions (lanes 7-10) show that a single polypeptide was released from the resin. The standard protein sizes are shown in $\mathrm{kDa}$ on the right side of the gel. 


\section{Figure 3. Endogenous MDH-1 and MDH-2 purifications}

\section{A}

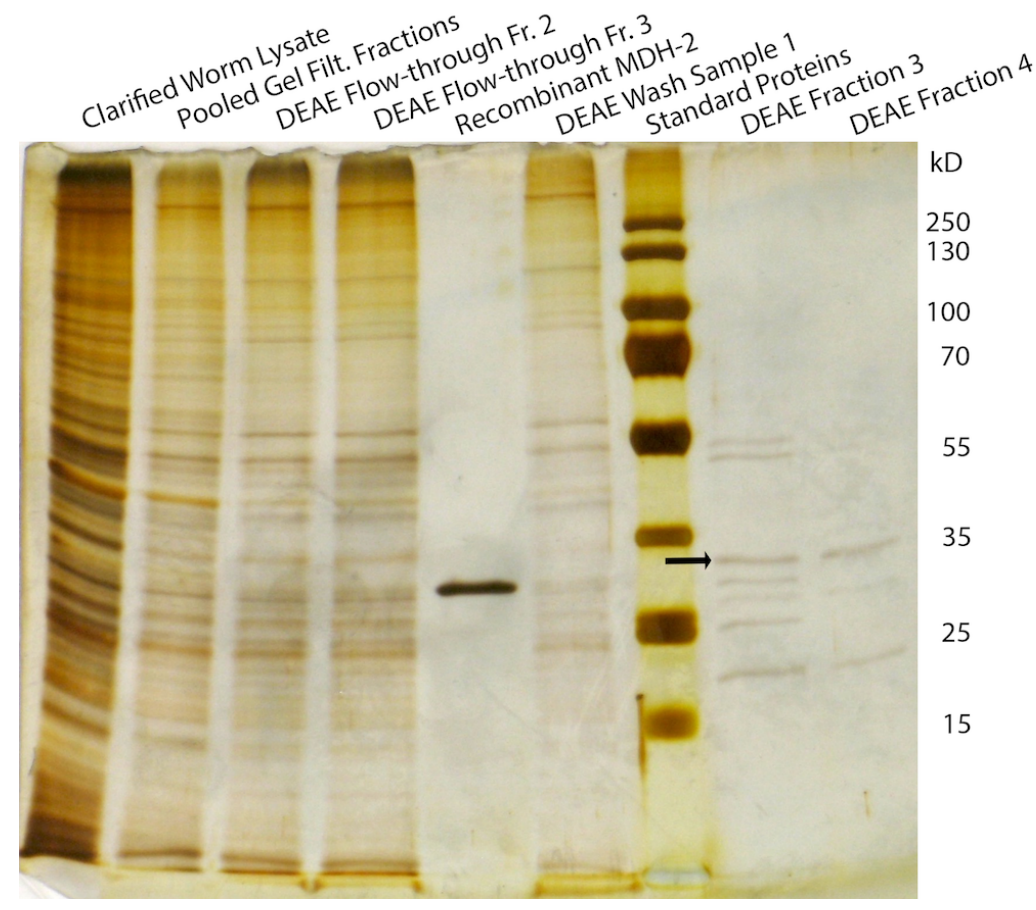

B

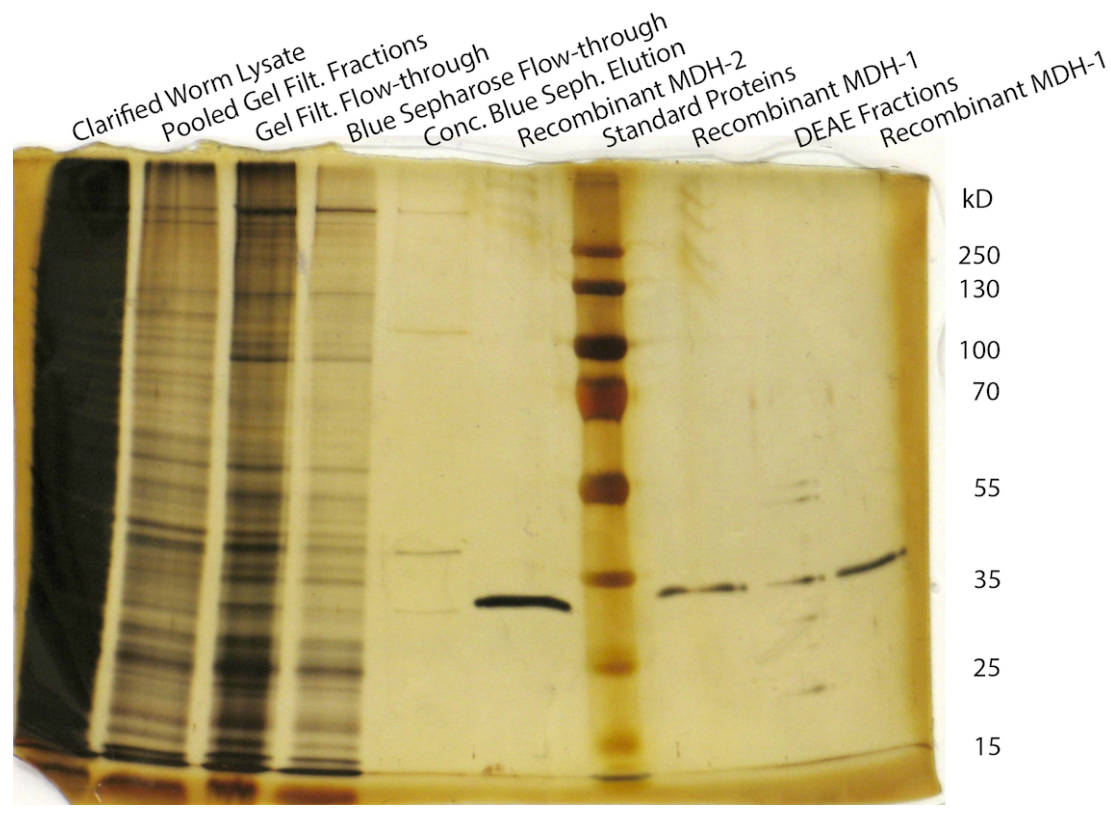


Figure 3. Endogenous MDH-1 and MDH-2 purification
A. Samples from a partial purification of endogenous $\mathrm{MDH}-1$ and $\mathrm{MDH}-2$ are shown in a $11 \%$ SDS-PAGE gel. The clarified worm lysate was run through a gel filtration column to change the buffer to $50 \mathrm{mM} \mathrm{CAPS}, \mathrm{pH} 9.5$, and $10 \mathrm{mM} \mathrm{KCl}$. The gel filtration fractions were loaded onto a DEAE column equilibrated in the same buffer. The flow-through samples from the DEAE column contained $\mathrm{MDH}-2$, and then the $\mathrm{KCl}$ concentration was increased to $50 \mathrm{mM}$ in the same buffer to remove $\mathrm{MDH}-1$ from the column. Lanes 8 and 9 show the $\mathrm{MDH}-1$-containing samples with $\mathrm{MDH}-1$ labeled with an arrow. The sizes of the protein standards are shown in $\mathrm{kDa}$.

B. Samples from a second partial purification of endogenous MDH-1 and MDH-2 are shown in a $10 \%$ SDS-PAGE gel. The purification was performed in the same way as shown in $3 \mathrm{~A}$. However, the DEAE flow-through samples were loaded onto a Blue Sepharose column in $50 \mathrm{mM}$ potassium phosphate, $\mathrm{pH} 7.5$, to further purify $\mathrm{MDH}-2$. The final $\mathrm{MDH}-2$ sample was eluted with $600 \mathrm{mM} \mathrm{KCl}$ in the same buffer and is shown in lane 5 next to recombinant $\mathrm{MDH}-2$ in lane 6 . The endogenous $\mathrm{MDH}-1$ sample (fractions 3-5 combined from the DEAE column) is shown in lane 9 between two samples of endogenous MDH-1 in lanes 8 and 10. The sizes of the protein standards are shown in $\mathrm{kDa}$. 
Figure 4. MDH-1 and MDH-2 Enzyme Kinetics

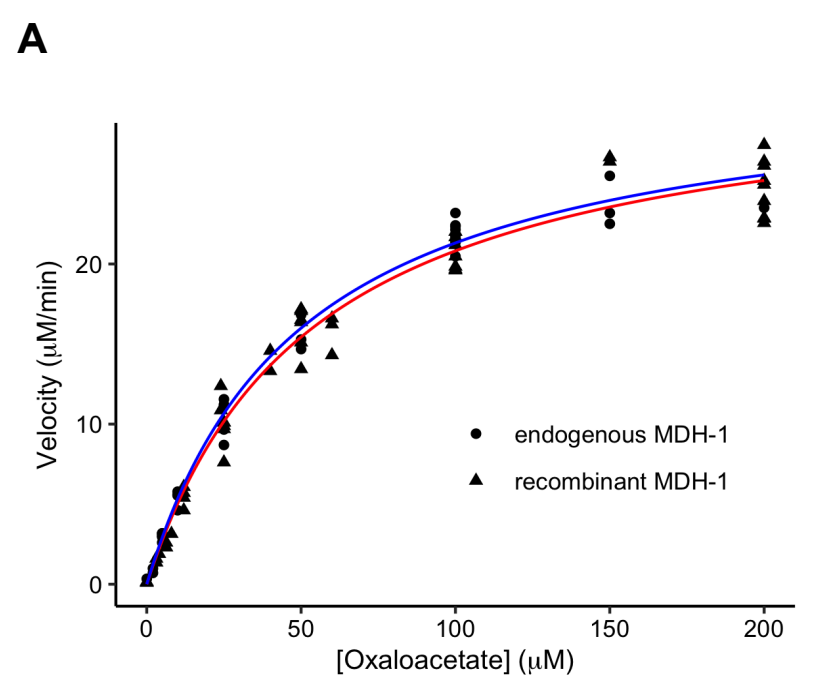

B

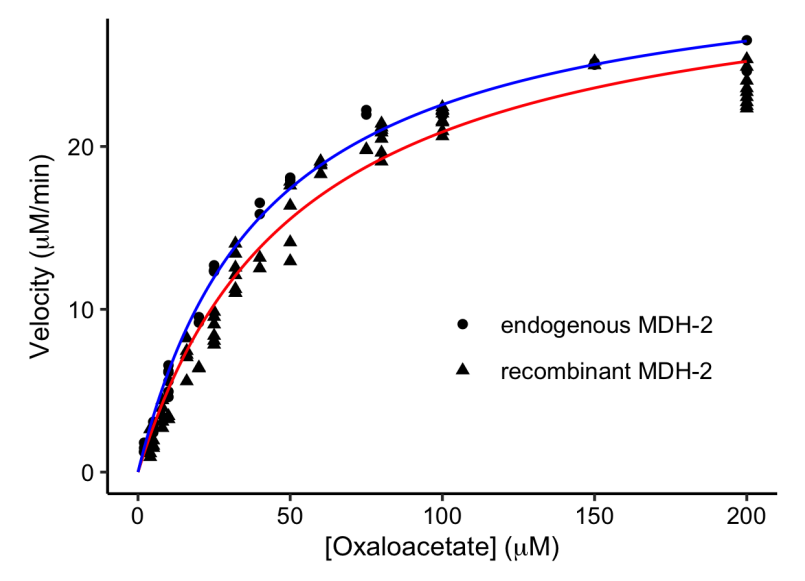

C

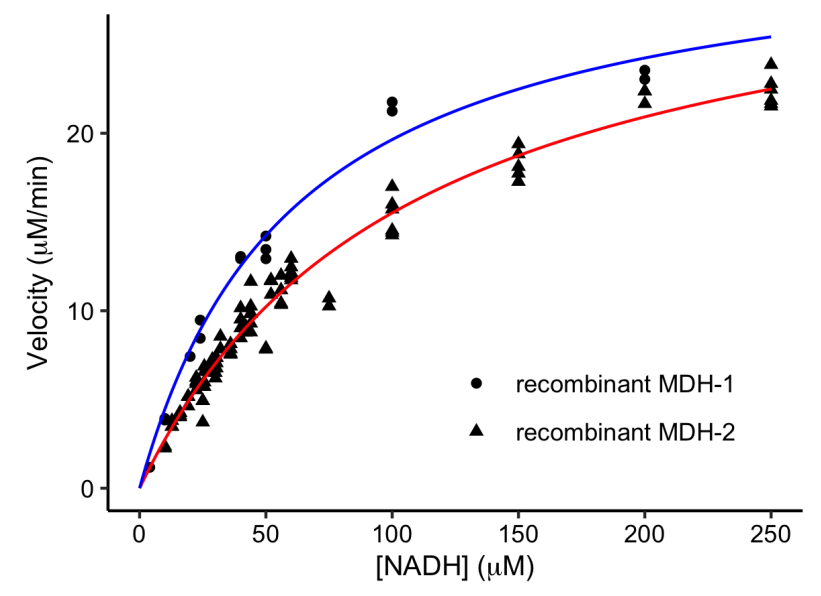


Figure 4. MDH-1 and MDH-2 Enzyme Kinetics

Enzyme velocities of recombinant (triangles) and endogenous (circles) MDH-1 (A) and MDH-2 (B) are shown as oxaloacetate was varied. The rate of change of absorbance at $340 \mathrm{~nm}$ was monitored as $\mathrm{NADH}$ was covered to $\mathrm{NAD}^{+}$during the reaction, and this was converted to $\mu \mathrm{M} / \mathrm{min}$. All of the data points are shown from replicate experiments performed at least twice. For these graphs, the data were normalized so that the $V_{\max }$ values were the same for each enzyme. The data were fit to the Michaelis-Menten equation, and the best-fit lines are shown in red and blue for recombinant and endogenous enzymes, respectively. The reaction conditions were $0.1 \mathrm{M}$ sodium phosphate buffer, $\mathrm{pH} 7.5,0.1 \mathrm{M} \mathrm{KCl}, 100 \mu \mathrm{M}$ $\mathrm{NADH}$, and oxaloacetate was varied from 0 to $200 \mu \mathrm{M}$ at $24{ }^{\circ} \mathrm{C}$. C. Enzyme velocities of recombinant $\mathrm{MDH}-1$ (circles, blue line) and $\mathrm{MDH}-2$ (triangles, red line) are shown as NADH was varied. The procedures were the same as described for $4 \mathrm{~A}$ and $4 \mathrm{~B}$, except that $150 \mu \mathrm{M}$ oxaloacetate was used, and the $\mathrm{NADH}$ concentration was varied from 0 to $250 \mu \mathrm{M}$. 
Figure 5. Temperature-dependence of $\mathrm{MDH}-1$ and $\mathrm{MDH}-2$ enzyme activity

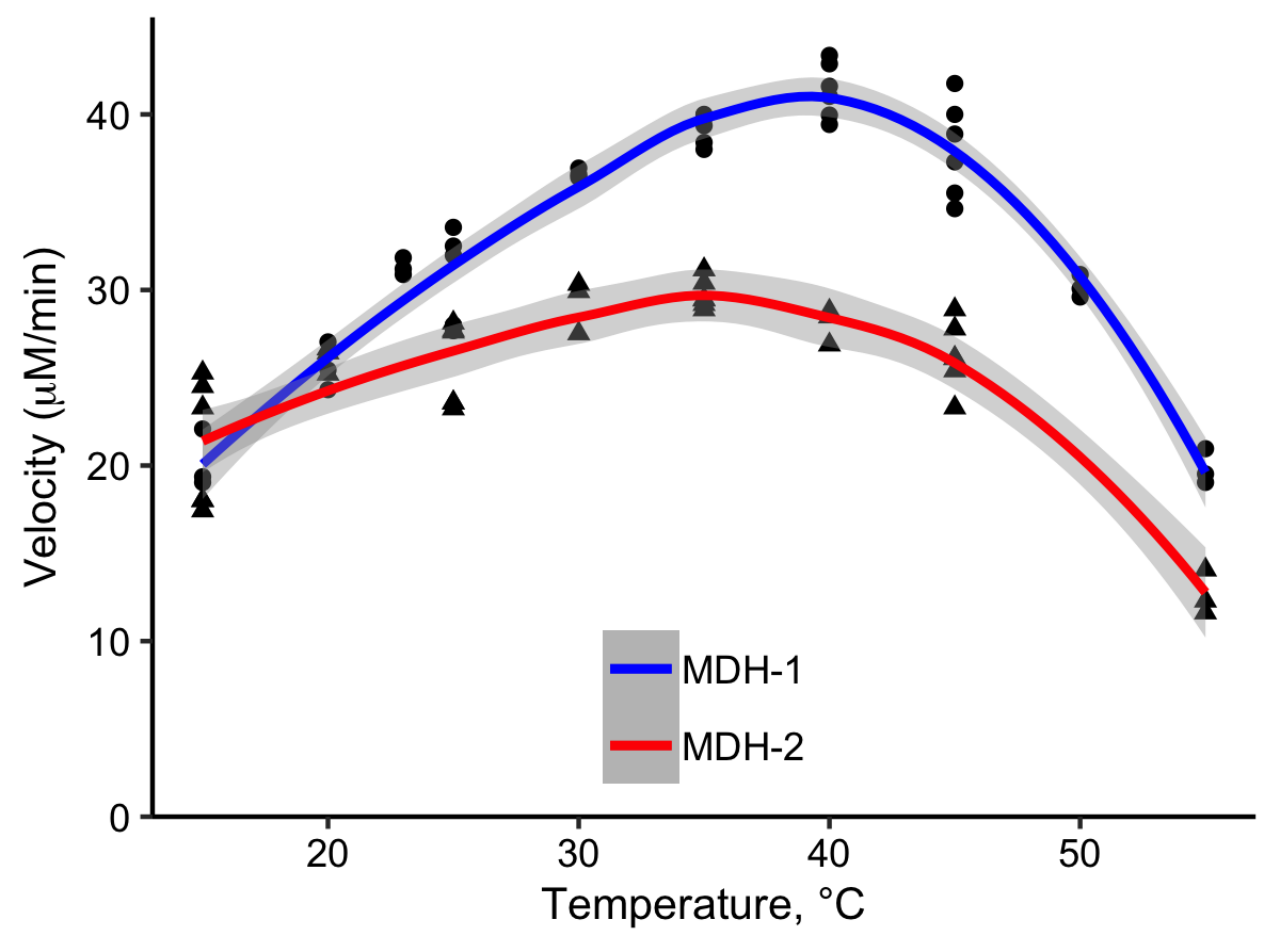

Figure 5. Temperature-dependence of MDH-1 and MDH-2 enzyme activity

Enzyme kinetics experiments were performed with $\mathrm{MDH}-1$ (circles) and $\mathrm{MDH}-2$ (triangles) at temperatures from 15 to $55^{\circ} \mathrm{C}$. The reaction conditions were $0.1 \mathrm{M}$ sodium phosphate buffer, $\mathrm{pH} 7.5,0.1 \mathrm{M} \mathrm{KCl}, 100 \mu \mathrm{M} \mathrm{NADH}$, and $150 \mu \mathrm{M}$ oxaloacetate. The data were smoothed using the Loess method, and the best-fit lines (blue for $\mathrm{MDH}-1$ and red for $\mathrm{MDH}-2$ ) and 95\% confidence intervals (gray) are shown. All of the data points are shown from replicate experiments performed at least twice. The velocity values were normalized using the average value at $20^{\circ} \mathrm{C}$. 


\section{Figure 6. Thermostability of recombinant MDH-1 and MDH-2}

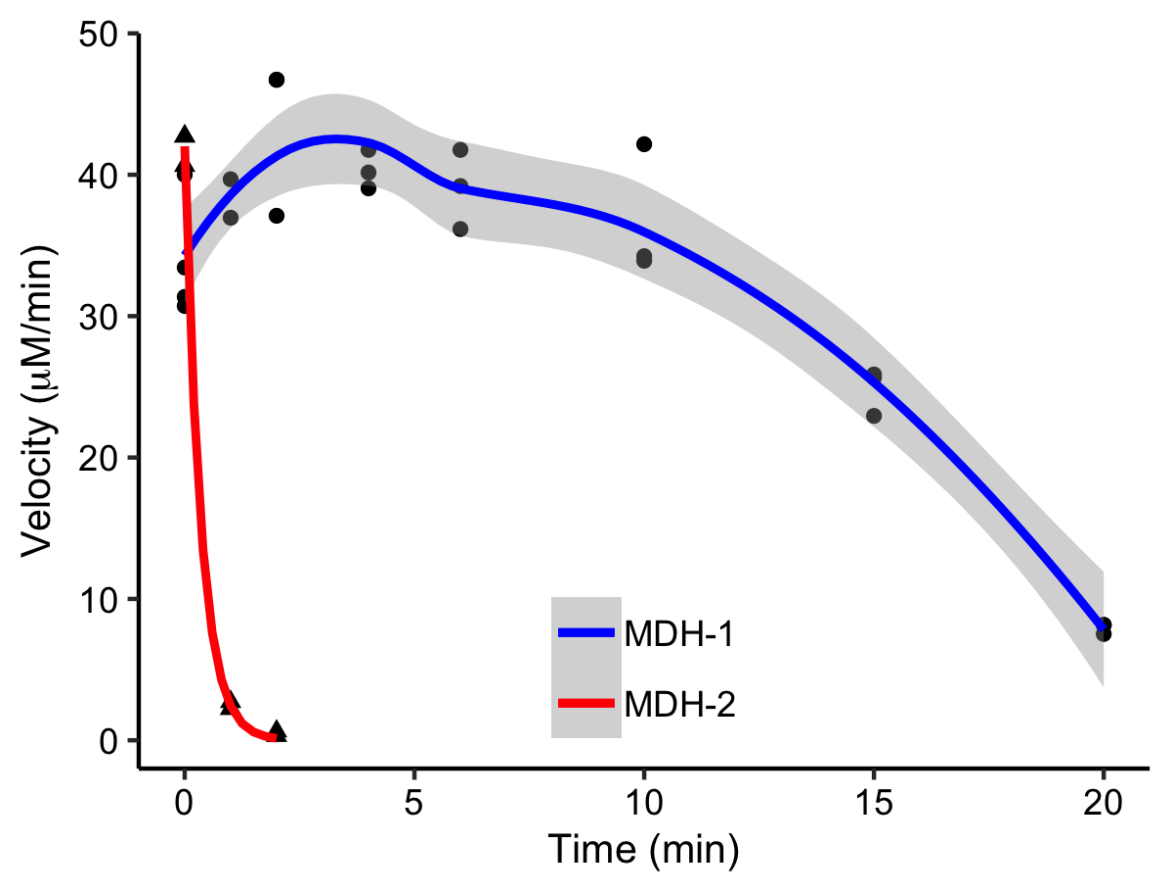

Figure 6. Thermostability of recombinant $\mathrm{MDH}-1$ and $\mathrm{MDH}-2$

Recombinant MDH-1 and MDH-2 in $50 \mathrm{mM}$ Tris buffer, $\mathrm{pH} 7.5$, and $0.5 \mathrm{mM}$ $\mathrm{NADH}$ were placed in a water bath at $55-57^{\circ} \mathrm{C}$ for times ranging from $0-20 \mathrm{~min}$. At each time point, enzyme samples were taken and used immediately for enzyme kinetics measurements. The enzyme kinetics reaction conditions were $0.1 \mathrm{M}$ sodium phosphate buffer, $\mathrm{pH} 7.5,0.1 \mathrm{M} \mathrm{KCl}, 100 \mu \mathrm{M} \mathrm{NADH}, 150 \mu \mathrm{M}$ oxaloacetate, and $24{ }^{\circ} \mathrm{C}$. The data were smoothed using the Loess method (for $\mathrm{MDH}-1$ ) and fit to an exponential (for MDH-2). The best-fit lines (blue for $\mathrm{MDH}-1$ and red for $\mathrm{MDH}-2$ ) and the $95 \%$ confidence interval for $\mathrm{MDH}-1$ (gray) are shown. The rate constant for inactivation of $\mathrm{MDH}-2$ was $2.85 \pm 0.18 \mathrm{~min}^{-1}$ (st. error). All of the data points are shown from replicate experiments performed twice. 
Figure 7. Intersubunit ionic interactions predicted in MDH-1

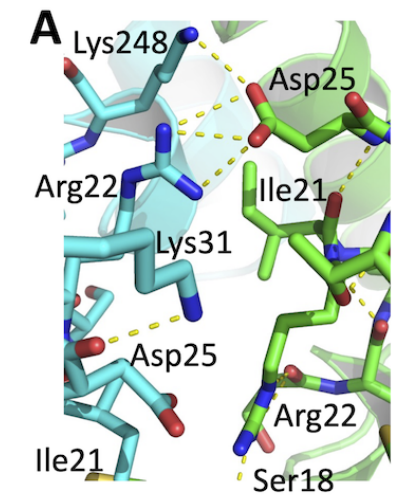

MDH-1 (model)

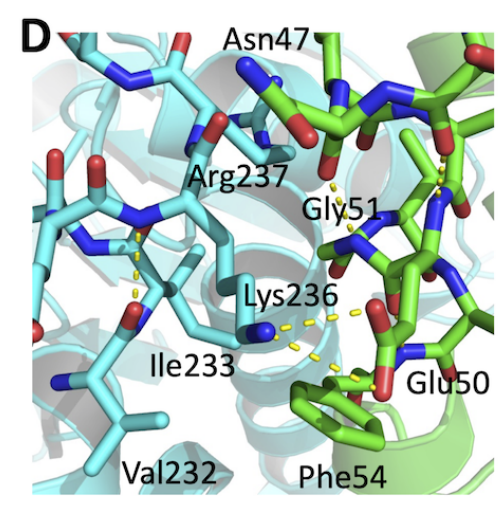

B

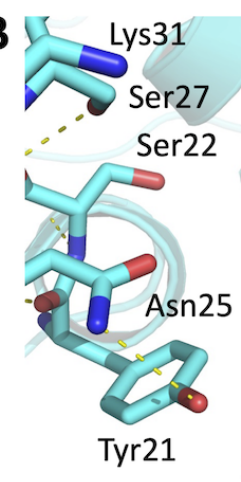

S. s. $\mathrm{MDH} 1(5 \mathrm{MDH})$

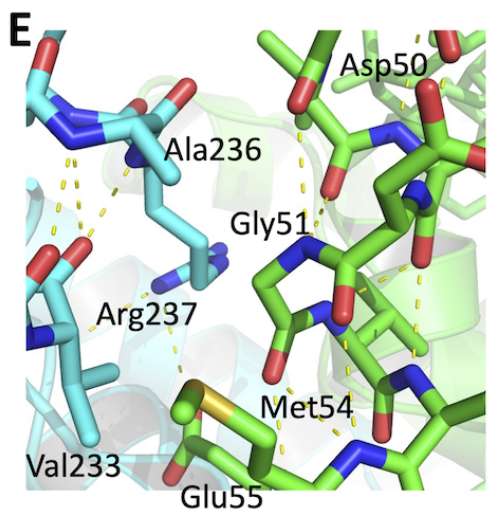

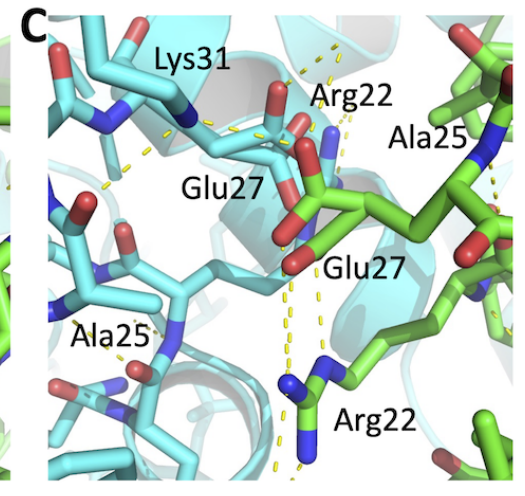

T. t. $\mathrm{MDH}(1 \mathrm{BMD})$

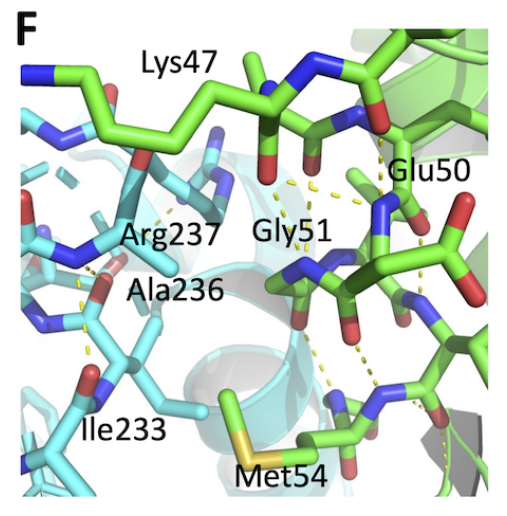

Figure 7. Intersubunit ionic interactions predicted in $\mathrm{MDH}-1$

PyMOL was used to visualize the predicted novel ionic hydrogen bonds in the $\mathrm{MDH}-1$ structural model (based on the 1BMD structure), and the corresponding views of $S$. scrofa MDH1 (5MDH) and T. thermophilus MDH (1BMD). Hydrogen bonds are indicated by the dashed yellow lines. Subunit $A$ is shown in green and subunit $B$ in teal. Amino acid numbering corresponds to the $S$. scrofa MDH1 sequence shown in Figure 1A. A. The hydrogen bonds between Asp25 and Arg22 and Lys248 are shown in MDH-1 with the surrounding amino acids. B. $\mathrm{MDH} 1$ has Asn25 and Ser22, which are not close enough to form a hydrogen bond. C. T. thermophilus MDH has a different, novel ionic interaction in this location between Glu27 and Lys31. (The 1BMD structure file shows Glu27 in two equally likely conformations (25)). This enzyme has an Ala25. D. The hydrogen bonds between Glu50 and Lys236 in MDH-1 are shown. E. MDH1 has an Ala236, so the same hydrogen bond can't form. Instead, this view shows a different hydrogen bond, Glu55 to Arg237, that is shared with MDH-1 but not visible in D. F. T. thermophilus MDH also has an Ala236, and it has no predicted intersubunit hydrogen bonds in this view. 